\title{
ENVOLVIMENTO DA REGIÃO COMISSURAL DO NÚCLEO DO TRATO SOLITÁRIO NAS RESPOSTAS CARDIOVASCULARES E SIMPÁTICAS PROMOVIDAS PELA INJEÇÃO DO ANTI-HIPERTENSIVO DE AÇÃO CENTRAL MOXONIDINA EM RATOS
}

Dissertação apresentada ao Programa de PósGraduação em Fisiologia Humana do Instituto de Ciências Biomédicas da Universidade de São Paulo, para obtenção do Titulo de Mestre em Ciências. 


\section{ENVOLVIMENTO DA REGIÃO COMISSURAL DO NÚCLEO DO TRATO SOLITÁRIO NAS RESPOSTAS CARDIOVASCULARES E SIMPÁTICAS PROMOVIDAS PELA INJEÇÃO DO ANTI-HIPERTENSIVO DE AÇÃO CENTRAL MOXONIDINA EM RATOS}

Dissertação apresentada ao Programa de PósGraduação em Fisiologia Humana do Instituto de Ciências Biomédicas da Universidade de São Paulo, para obtenção do Titulo de Mestre em Ciências.

Área de concentração: Fisiologia Humana

Orientador: Prof. Dr. Thiago dos Santos Moreira

Versão corrigida. A versão original eletrônica encontra-se disponível tanto na Biblioteca do ICB quanto na Biblioteca Digital de Tese e Dissertação da USP (BDTD). 
DADOS DE CATALOGAÇÃO NA PUBLICAÇÃO (CIP)

Serviço de Biblioteca e Informação Biomédica do

Instituto de Ciências Biomédicas da Universidade de São Paulo

\section{() reprodução total}

\section{Totola, Leonardo Tedesco.}

Envolvimento da região comissural do núcleo do trato solitário nas respostas cardiovasculares e simpáticas promovidas pela injeção do anti-hipertensivo de ação central moxonidina em ratos / Leonardo Tedesco Totola. -- São Paulo, 2013

\section{Orientador: Prof. Dr. Thiago dos Santos Moreira.}

Dissertação (Mestrado) - Universidade de São Paulo. Instituto de Ciências Biomédicas. Departamento de Fisiologia e Biofísica. Area de concentração: Fisiologia Humana. Linha de pesquisa: Controle neural cardiorrespiratório

Versão do título para o inglês: Involvement of the commissural nucleus of the solitary tract in cardiovascular and sympathetic responses elicted by the anti-hypertensive drug moxonidine in rats.

1. Atividade simpática 2. Hipertensão 3 . Moxonidina 4. Núcleo do trato solitário 5. Bulbo ventrolateral rostral I. Moreira, Prof. Dr. Thiago dos Santos II. Universidade de São Paulo. Instituto de Ciências Biomédicas. Programa de Pós-Graduação em Fisiologia Humana III. Título. 
UNIVERSIDADE DE SÃO PAULO

INSTITUTO DE CIÊNCIAS BIOMÉDICAS

Candidato(a): $\quad$ Leonardo Tedesco Totola.

Título da Dissertação: $\quad$ Envolvimento da região comissural do núcleo do trato solitário nas respostas cardiovasculares e simpáticas promovidas pela injeção do anti-hipertensivo de ação central moxonidina em ratos.

Orientador(a): $\quad$ Prof. Dr. Thiago dos Santos Moreira.

A Comissão Julgadora dos trabalhos de Defesa da Dissertação de Mestrado, em sessão pública realizada a I.

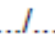
, considerou
( ) Aprovado(a)
( ) Reprovado(a)

Examinador(a): Assinatura:

Instituição:

Examinador(a): Assinatura:

Nome:

Instituição:

Presidente: Assinatura:

Nome:

Instituição: 


\section{Certificado}

Certificamos que o protocolo registrado sob $n^{\circ} \mathbf{8 5}$ nas fls. 90 do livro $\mathbf{0 2}$ para uso de animais em experimentação, sob a responsabilidade do Prof(a) Dr(a) Thiago dos Santos Moreira, Coordenador(a) da Linha de pesquisa Participação do núcleo do rato solitário comissural nas respostas cardiorrespiratórias produzidas pela injeção de moxonidina do qual participam o(s) alunos Leonardo Tedesco Totola, está de acordo com os Principios Éticos de Experimentação Animal adotado pela Sociedade Brasileira de Ciência de Animais de Laboratório (SBCAL) e foi aprovado pela COMISSÃO DE ÉTICA NO USO DE ANIMAIS (CEUA) em 19.08.2010, com validade de 3 anos.

São Paulo, 20 de agosto de 2010 .

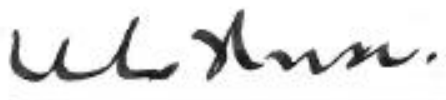

Prof.Dr.Wothan TAvares DE LIMA Coordenador CEUA - ICB/USP

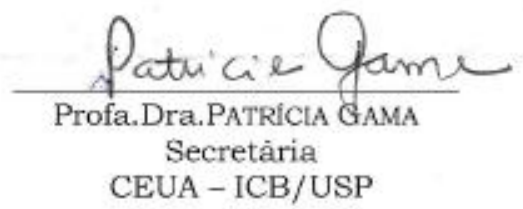


Este trabalho é dedicado a todos os familiares e em especial a minha esposa e minha filha, que no período de desenvolvimento deste trabalho me ajudaram com paciência, carinho e muita compreensão.

O meu muito obrigado! 


\section{AGRADECIMENTOS}

Agradeço a Deus por me dar força para continuar e sempre seguir em frente com os meus objetivos.

Ao meu orientador Prof. Dr. Thiago dos Santos Moreira, por abrir as portas do seu laboratório, confiança depositada, paciência e acima de tudo pelos ensinamentos. Por ti, tenho muita admiração e serei sempre grato.

À Prof. Dra. Ana Carolina T. Takakura pelo apoio e sugestões ao meu projeto.

Aos professores presente na banca examinadora de defesa, pela avaliação, leitura atenção dispensada.

Ao meu pai Gilmar, minha mãe Ana Marcia, meu irmão Eduardo, minha esposa Marília e sua família e em especial a minha filha linda Priscila, um presente que ganhei no final do meu projeto, agradeço a todos pelo carinho, compreensão, força e acima de tudo o incentivo a seguir em frente, obrigado por vocês estarem presente na minha vida e poderem compartilhar esse momento.

A todos os meus amigos, em especial o Rodrigo, que me deu força e incentivo para começar o mestrado e após contribuindo com varias discussões, obrigado.

Ao Thales, Cleyton e Hildebrando amigos e irmãos que fiz no laboratório dividindo o mesmo setup e ajuda nos experimentos, como não podia esquecer as nossas varias discussões onde sempre tive a razão, o meu muito obrigado.

Aos membros do laboratório de cardiorrespiratório, controle neural cardiorrespiratório e controle neural da circulação, pela experiência compartilhada sobre o meu projeto. Ao Renatinho, Joaozinho, Merise, Areinha, Jurema, Guta, In ching, pela força e ensinamentos.

A todos os professores que me ajudaram a chegar aqui com os conhecimentos adquirido nas aulas.

Aos meus colegas que construir no ICB e aos técnicos que me ajudaram com os conhecimentos adquiridos no laboratório.

A Santa Casa, por me liberar para participar em congressos e simpósio.

A todos que contribuíram e torceram os meus sinceros agradecimentos. 
"Existem momentos em nossas vidas, em que as palavras perdem o sentido ou parecem inúteis, e por mais que pensemos numa forma de empregá-las elas parecem não servir... Então agente não diz apenas sente."

Sigmund Freud

"O professor não é o que ensina, mais o que desperta no aluno a vontade de aprender." Jean Piaget 


\section{RESUMO}

TOTOLA, L. T. Envolvimento da região comissural do núcleo do trato solitário nas respostas cardiovasculares e simpáticas promovidas pela injeção do antihipertensivo de ação central moxonidina em ratos. 2013. 75 f. Dissertação (Mestrado em Fisiologia Humana) - Instituto de Ciências Biomédicas, Universidade de São Paulo, São Paulo, 2013.

Os agonistas adrenérgicos $\alpha_{2}$ e imidazólicos mais utilizados e estudados são a clonidina, rilmenidina e a moxonidina. Esta bem estabelecido na literatura que esses fármacos têm sua ação no sistema nervoso central (SNC), mais especificamente na região rostroventrolateral do bulbo (RVL/C1). No entanto, no presente trabalho, testamos a hipótese de que a moxonidina possa produzir suas respostas antihipertensivas (redução da atividade simpática e pressão arterial) atuando também em outra importante estrutura bulbar, como o núcleo do trato solitário comissural (NTScom). Para isso, foram registrados a pressão arterial media (PAM), frequência cardíaca (FC), a atividade simpática eferente do nervo esplâncnico (AS) e a atividade elétrica dos neurônios pré-motores simpáticos localizados na região RVL/C1. Foram utilizados dois grupos de ratos Wistar (280-320 g, $\mathrm{n}=5-7 /$ grupo): a) anestesiados com uretana (1,2 $\mathrm{g} / \mathrm{kg}$, iv) e ventilados artificialmente e b) ratos não anestesiados com implante de canulas de aço inoxidável na região do NTScom ou no quarto ventrículo encefálico $\left(4^{\circ} \mathrm{V}\right)$. Nossos resultados, em ratos não anestesiados, mostraram que a hipotensão produzida pela injeção de moxonidina $(20 \mathrm{nmol} / 1 \mu \mathrm{l})$ no $4^{\circ} \mathrm{V}$ foi reduzida $(\Delta=-14 \pm 3$, vs. lesão fictícia: $\Delta=-36 \pm 5 \mathrm{mmHg})$ após a lesão eletrolítica do NTScom. Ademais, a injeção de moxonidina (1, 2.5 e 5 $\mathrm{nmol} / 50 \mathrm{nl})$ no NTScom reduziu a PAM $(\Delta=-7 \pm 3,-17 \pm 4$ e $-28 \pm 6$, vs. veículo: $\Delta=$ $+4 \pm 3 \mathrm{mmHg})$ e a FC ( $\Delta=-10 \pm 4,-22 \pm 3$ e $-27 \pm 4$, vs. veículo: $\Delta=+5 \pm 2 \mathrm{bpm})$. Em animais anestesiados, a moxonidina $(2,5$ e $5 \mathrm{nmol} / 50 \mathrm{nl})$ injetada no NTScom produziu hipotensão ( $\Delta=-12 \pm 3$ e $-24 \pm 4 \mathrm{mmHg}$, vs. veículo: $\Delta=+3 \pm 3 \mathrm{mmHg}$ ), bradicardia ( $\Delta=-18 \pm 5$ e $-25 \pm 9$ bpm, vs. veículo: $\Delta=+3 \pm 4 \mathrm{bpm}$ ) e redução da $A S$ ( $\Delta=-11 \pm 2$ e $-25 \pm 3 \%$, vs. veículo: $\Delta=+2 \pm 2 \%$ ). A injeção do antagonista de receptores adrenérgicos $\alpha_{2}$ ioimbina $(10 \mathrm{nmol} / 50 \mathrm{nl})$ ou $\mathrm{RX} 821007(10 \mathrm{nmol} / 50 \mathrm{nl})$ no NTScom foi capaz de bloquear as respostas hipotensora $(\Delta=-3 \pm 2$ e $-5 \pm 7$ $\mathrm{mmHg}$, vs. moxonidina: $\Delta=-22 \pm 4 \mathrm{mmHg})$ e a simpatoinibição $(\Delta=-2 \pm 5$ e $-3 \pm$ $4 \%$, vs. moxonidina: $\Delta=-18 \pm 3 \%$ ) produzida pela injeção de moxonidina ( $5 \mathrm{nmol} / 50$ $\mathrm{nl})$ no NTScom. A injeção bilateral de moxonidina $(1,2,5$ e $5 \mathrm{nmol} / 50 \mathrm{nl})$ na região RVL/C1 reduziu PAM ( $\Delta=-15 \pm 5,-27 \pm 4$ e $-37 \pm 5$, vs. veículo: $\Delta=+6 \pm 4 \mathrm{mmHg})$ e AS $(\Delta=-18 \pm 6,-42 \pm 4$ e $-61 \pm 7 \%$, vs. veículo: $\Delta=+5 \pm 3 \%)$. Adicionalmente, foram registrados 15 neurônios da região do $\mathrm{RVL} / \mathrm{C} 1$. A injeção de moxonidina (5 $\mathrm{nmol} / 50 \mathrm{nl}$ ) no NTScom promoveu uma redução da atividade dos neurônios prémotores simpáticos do RVL/C1 (15 $\pm 1.8 \mathrm{~Hz}$, vs. veículo: $21.3 \pm 1.2 \mathrm{~Hz})$, compatível com a redução da pressão arterial $(\Delta=-22 \pm 4 \mathrm{mmHg})$ promovida pela injeção de moxonidina no NTScom. Dez neurônios foram imunorreativos para tirosina hidroxilase $(\mathrm{TH})$ e cinco neurônios não foram imunorreativos para $\mathrm{TH}$. Os nossos resultados sugerem que a moxonidina pode estar atuando também em outra estrutura importante do bulbo (NTScom) para produzir os seus efeitos antihipertensivos.

Palavras-chave: Atividade simpática. Hipertensão. Moxonidina. Núcleo do Trato Solitário. Bulbo Ventrolateral Rostral. 


\section{ABSTRACT}

TOTOLA, L. T. Involvement of the commissural nucleus of the solitary tract in cardiovascular and sympathetic responses elicited by the anti-hypertensive drug moxonidine in rats. 2013. 75 p. Masters thesis (Human Physiology) - Instituto de Ciências Biomédicas, Universidade de São Paulo, São Paulo, 2013.

The $\alpha_{2}$ adrenergic and imidazoline agonists are important antihypertensive drugs used in clinical medicine. They are classified as central antihypertensive drugs and the most used and studied are clonidine, rilmenidine and moxonidine. The rostral ventrolateral medulla/C1 region (RVLM/C1) contains the presympathetic neurons involved in cardiovascular regulation that has been implicated as one of the most important central sites for the antihypertensive action of moxonidine. However, in the present study, we tested the hypothesis that moxonidine produces its antihypertensive response (reduction of sympathetic activity and arterial pressure) also by acting in another important brainstem region, as the commissural nucleus of the solitary tract (commNTS). Mean arterial pressure (MAP), heart rate (HR), splanchnic sympathetic nerve activity (sSNA) and activity of putative sympathoexcitatory vasomotor neurons of the RVLM were recorded in conscious or urethane-anesthetized, and artificial ventilated male Wistar rats $(280-320 \mathrm{~g}, \mathrm{n}=5$ $7 /$ grupo). In non-anesthetized rats, the hypotension elicited by moxonidine $(20 \mathrm{nmol} / 1$ $\mu \mathrm{l})$ into the fourth brain ventricle (4th $\mathrm{V})$ was reduced $(\Delta=-14 \pm 3$ vs. sham lesion: $\Delta$ $=-36 \pm 5 \mathrm{mmHg}$ ) after electrolytic lesion of the commmNTS. Moreover, moxonidine $(1,2.5$ and $5 \mathrm{nmol} / 50 \mathrm{nl})$ injected into the commNTS decreased MAP $(\Delta=-7 \pm 3,-17$ \pm 4 and $-28 \pm 6$ vs. vehicle: $\Delta=+4 \pm 3 \mathrm{mmHg})$ and $\mathrm{HR}(\Delta=-10 \pm 4,-22 \pm 3$ and $-27 \pm$ 4 vs. vehicle: $\Delta=+5 \pm 2 \mathrm{bpm}$ ). In urethane-anesthetized rats, moxonidine (2.5 and 5 $\mathrm{nmol} / 50 \mathrm{ml})$ into the commNTS produced hypotension $(\Delta=-12$ and $-24 \pm 3 \pm 4$ mmHg vs. vehicle: $\Delta=3 \pm 3 \mathrm{mmHg}$ ), bradycardia $(\Delta=-18 \pm 5$ and $-25 \pm 9$ bpm vs. vehicle: $\Delta=3 \pm 4 \mathrm{bpm})$ and sympathoinhibition $(\Delta=-11 \pm 2$ and $-25 \pm 3 \%$ vs. vehicle: $2 \pm 2 \%$ ). The injection of the $\alpha_{2}$ adrenergic receptor antagonist yohimbine (10 $\mathrm{nmol} / 50 \mathrm{ml})$ or $\mathrm{RX821002}(10 \mathrm{nmol} / 50 \mathrm{nl})$ into the commNTS blocked the hypotension ( $\Delta=-3 \pm 2$ e $-9 \pm 5 \mathrm{mmHg}$, vs. moxonidina: $\Delta=-22 \pm 4 \mathrm{mmHg}$ )and the reductrion in SSNA ( $\Delta=-2 \pm 5$ e $-11 \pm 7 \%$, vs. moxonidina: $\Delta=-18 \pm 3 \%$ ) elicited by moxonidine $(5 \mathrm{nmol} / 50 \mathrm{nl})$. Moxonidine $(1,2.5$ and $5 \mathrm{nmol} / 50 \mathrm{ml})$ injected bilaterally in the $\mathrm{RVLM} / \mathrm{C} 1$ region reduced MAP $(\Delta=-15 \pm 5-27 \pm 4-37 \pm 5$ and, vs. vehicle: $\Delta$ $=+6 \pm 4 \mathrm{mmHg})$ and sSNA $(\Delta=-18 \pm 6,-42 \pm 4$ and $-61 \pm 7 \%$, vs. veículo: $\Delta=+5 \pm$ $3 \%)$. Additionally, 15 neurons were recorded in the region of $R V L M / C 1 \quad(N=2-3$ neurons/ rats, $\mathrm{N}=6$ rats). On average, moxonidine $(5 \mathrm{nmol} / 50 \mathrm{nl})$ into the commNTS elicited a reduction in the activity of sympathetic premotor neurons of RVLM/C1 (15 \pm $1.8 \mathrm{~Hz}$, vs. vehicle: $21.3 \pm 1.2 \mathrm{~Hz}, 28 \%$ reduction), consistent with a reduction in blood pressure $(\Delta=-22 \pm 4 \mathrm{mmHg})$ produced by moxonidine into the commNTScom. Ten neurons were tyrosine hydroxylase-immunoreactive (TH-ir) and five were not. All the cells were found within the cluster of $\mathrm{TH}$-ir neurons that defines the pressor region of the RVLM. Our results suggest that moxonidine may also be acting in another important structure of the brainstem (commNTS) to produce their antihypertensive effects.

Keywords: Sympathetic Activity. Hypertension. Moxonidine. Commissural Nucleus of the Solitary Tract. Ventrolateral Medulla. 


\section{LISTA DE ILUSTRAÇÕES}

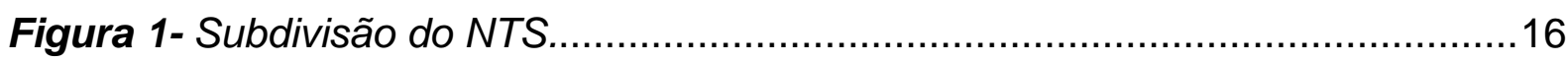

Figura 2- Registro extracelular dos neurônios do RVL. .......................................27

Figura 3- Injeção de moxonidina no quarto ventrículo em ratos com lesão eletrolítica da região comissural do NTS. 36

Figura 4 - Efeitos da lesão eletrolítica do NTScom nas respostas cardiovasculares promovidas pela ativação e desativação do barorreflexo e ativação do quimiorreflexo periférico. 37

Figura 5 - Injeção de moxonidina no NTScom em ratos não anestesiados. .40

Figura 6 - Efeitos cardiovasculares promovidos pela injeção de moxonidina no NTScom em ratos não anestesiados.

Figura 7 - Efeitos da injeção de moxonidina no NTScom nas respostas cardiovasculares promovidas pela ativação e desativação do barorreflexo e ativação do quimiorreflexo periférico.

Figura 8 - Localização da injeção de moxonidina no NTScom em ratos anestesiados e normotensos.

Figura 9 - Respostas cardiovasculares e simpáticas produzidas pela injeção de moxonidina no NTScom em ratos anestesiados.

Figura 10 - Respostas cardiovasculares e simpáticas produzidas pela injeção de moxonidina no NTScom em ratos que receberam a injeção prévia de ioimbina. 48 Figura 11- Respostas cardiovasculares e simpáticas produzidas pela injeção de moxonidina no NTScom em ratos que receberam a injeção prévia de $R$ X821002. ..49 Figura 12 - Localização da injeção de moxonidina na região RVL/C1 em ratos anestesiados.

Figura 13 - Respostas cardiovasculares e simpáticas produzidas pela injeção de moxonidina na região $R V L / C 1$ em ratos anestesiados. 52

Figura 14 - Efeitos da injeção de moxonidina no NTScom sobre a atividade elétrica dos neurônios pré-motores simpáticos do RVL/C1 em ratos anestesiados. .54

Figura 15 - Mecanismos neurais de controle cardiovascular. 
LISTA DE ABREVIATURAS E SIGLAS

cc

$\mathrm{CO}_{2}$

i.v

FC

GABA

$\mathrm{Gr}$

ICV

IML

$\mathrm{KCN}$

NTS

NTScom

PAM

PAP

PE

py

RVL

SHR

SNC

SSNA

Sp5

TH

$4^{\circ} \mathrm{V}$

XII

VII
Canal Central,

Dióxido de Carbono

Intravenosamente

Frequência Cardíaca

Ácido Gama-Aminobutírico

Núcleo Grácil

Intracerebroventricular

Coluna Intermédio-Lateral

Cianeto de Potássio

Núcleo do Trato Solitário

Núcleo do Trato Solitário Comissural

Pressão Arterial Média

Pressão Arterial Pulsátil

Polietileno

Pirâmide

Região Ventrolateral do Bulbo

Ratos Espontaneamente Hipertensos

Sistema Nervoso Central

Atividade do Nervo Simpático Esplâncnico

Trato Espinal do Trigêmio

Tirosina Hidroxilase

Quarto Ventrículo

Núcleo Motor do Hipoglosso

Núcleo Motor do Facial 


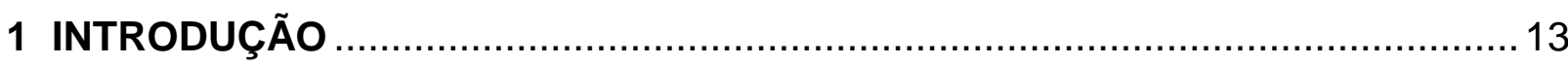

1.1 Regulação neural da pressão arterial ................................................. 13

1.2 Centro de integração de aferências cardiovasculares: núcleo do trato solitário

1.3 Mecanismos adrenérgicos no controle da pressão arterial

1.4 Principais teorias envolvidas nos mecanismos neurais de fármacos antihipertensivos de ação central: hipótese adrenérgica $\alpha_{2} \mathbf{X}$ hipótese imidazólico 19 2 HIPÓTESE 21

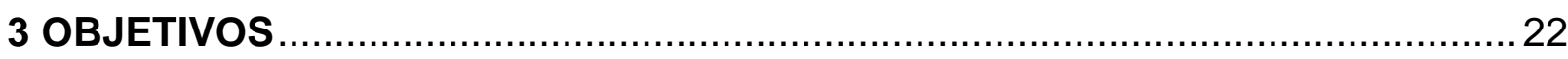

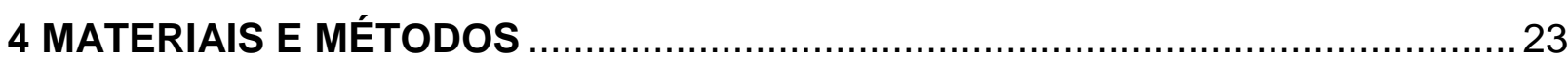

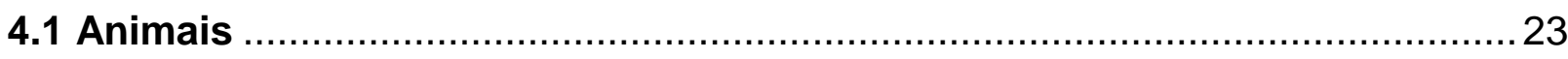

4.2 Lesão eletrolítica no núcleo do trato solitário comissural .........................23

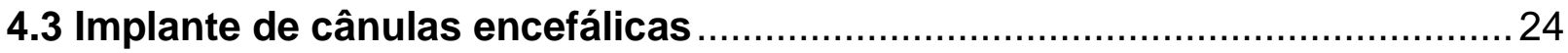

4.4 Registro da pressão arterial e da frequência cardíaca .............................24

4.5 Procedimentos cirúrgicos e anestésicos: experimentos em animais

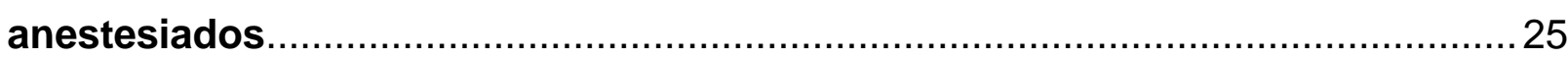

4.6 Medida da atividade do nervo esplâncnico.......................................... 26

4.7 Registro extracelular dos neurônios do RVL.......................................... 26

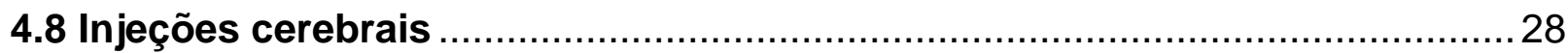

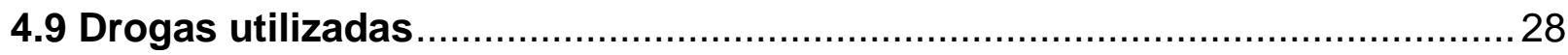

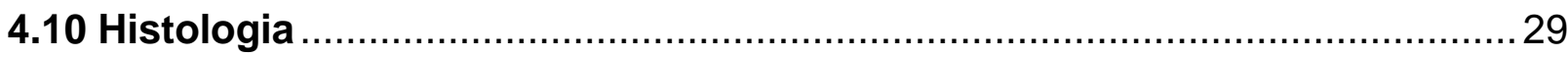

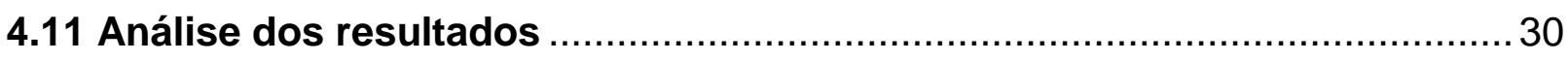

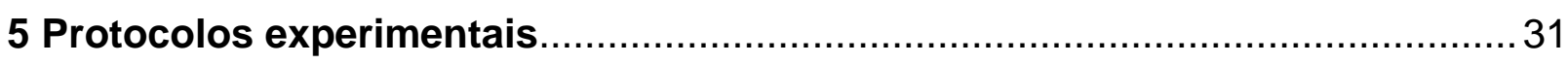

5.1 Efeitos cardiovasculares da injeção central (4ำ $)$ de moxonidina em ratos com lesão eletrolítica da região comissural do NTS

5.2 Efeitos cardiovasculares produzidos pela injeção de moxonidina na região do NTScom em ratos não anestesiados.

5.3 Respostas cardiovasculares e de atividade simpática produzidos pela injeção de moxonidina no NTScom ou no RVL/C1 em ratos anestesiados

5.4 Participação dos receptores adrenérgicos $\alpha_{2}$ nas respostas de hipotensão e simpatoinibição produzidas pela injeção de moxonidina no NTScom em ratos anestesiados. 
5.5 Efeitos produzidos pela injeção de moxonidina no NTScom na atividade elétrica dos neurônios pré-simpáticos da região RVL/C1 …...............................33

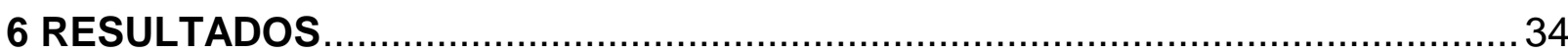

6.1 Efeitos da lesão eletrolítica do NTScom nas respostas cardiovasculares produzidas pela injeção de moxonidina no 4 $\mathrm{V}$ em ratos não anestesiados......34 6.2 - Efeitos cardiovasculares promovidos pela injeção de moxonidina no NTScom em ratos não anestesiados 38

6.3 Respostas cardiovasculares e simpáticas produzidas pela injeção de moxonidina no NTScom em ratos anestesiados

6.4 Respostas cardiovasculares e simpáticas promovidas pela injeção de moxonidina no NTScom após o bloqueio seletivo de receptores adrenérgicos $\alpha_{2}$

6.5 Respostas cardiovasculares e simpáticas produzidas pela injeção de moxonidina no RVL/C1 em ratos anestesiados 50

6.6 Efeitos da injeção de moxonidina no NTScom sobre a atividade elétrica dos neurônios pré-simpáticos do RVL/C1

7. DISCUSSÃO

7.1 Envolvimento da região comissural do NTS sobre os efeitos cardiovasculares e simpáticos induzidos pela moxonidina

7.2 Efeito comparativo da moxonidina injetada na região comissural do NTS e na região $\mathrm{RVL} / \mathrm{C} 1$

7.3 Inibição de neurônios pré-motores simpáticos da região RVL/C1 pela injeção de moxonidina na região comissural do NTS 61

8 CONCLUSÃO .64

REFERENCIAS* 


\section{INTRODUÇÃO}

O sistema cardiovascular apresenta uma importância essencial na regulação e manutenção da homeostasia do meio interno. Para desempenhar esta função primordial, esse complexo sistema dispõe de mecanismos refinados no ajuste da pressão arterial momento a momento (controle neural) e de longa duração (controle hormonal). No presente estudo, iremos nos concentrar nos mecanismos exercidos pelo sistema nervoso central (SNC) na regulação cardiovascular.

\subsection{Regulação neural da pressão arterial}

A regulação neural do sistema cardiovascular envolve a ativação de diferentes grupos de sensores periféricos (barorreceptores, receptores cardiopulmonares e quimiorreceptores), os quais projetam suas aferências para estruturas do SNC via nervo glossofaríngeo e nervo vago (IX e X pares de nervos cranianos, respectivamente). O processamento destas informações aferentes no SNC irá resultar na modulação das vias autônomas eferentes, controlando as variáveis cardiovasculares no sentido de manter a homeostase nas diversas situações comportamentais em que os mamíferos são submetidos. No sistema cardiovascular, as variáveis reguladas pelo sistema nervoso autônomo são a frequência cardíaca, o volume sistólico (força de contração) e a resistência vascular periférica, as quais são determinantes da pressão arterial.

O envolvimento do SNC na manutenção da homeostase do sistema cardiovascular é conhecido desde o século XIX. Os estudos clássicos realizados por Claude Bernard na França, e publicados em 1863* (apud GEBBER, 1990), já mostravam que a transecção da medula espinal cervical, em qualquer nível, produzia pronunciada queda da pressão arterial. No entanto, foram os estudos de Dittmar, em $1873^{\dagger}$ (apud GEBBER, 1990), que primeiro demonstraram a participação do bulbo na manutenção da pressão arterial, sobretudo as porções ventrolaterais bulbares. Nesses estudos, observou-se que a destruição da região ventrolateral do bulbo produzia queda da pressão arterial, ao passo que o mesmo não acontecia se

\footnotetext{
"BERNARD, C. Lençons sur phyologie et La pathologie du système nerveux. Bailliere, Paris, 1863. v. 1, p. 381.

$\dagger$ DITTMAR, C. Uber die Lage sogenannte Gefasscentriems in der Medulla oblongata. Ber. Verh. Saenchs. Wiss. Leipzing Math Phys., v. 125, p. 449-469, 1873.
} 
a destruição fosse realizada na região dorsal. Disso adveio a hipótese de que a região ventrolateral do bulbo exerceria fundamental importância na manutenção dos níveis considerados normais de pressão arterial, e foi introduzido na época o conceito de tônus vasomotor simpático.

Posteriormente, Bayliss lançou a hipótese de que existiria um centro vasomotor, localizado na região ventrolateral do bulbo, e que seria constituído por áreas tanto pressoras como depressoras (BAYLISS, 1901).

Mais tarde, o aparecimento da técnica de estereotaxia associada à eletrofisiologia possibilitou o mapeamento de todo o tronco encefálico e com isso, foram identificadas regiões pressoras e depressoras situadas em toda a formação reticular bulbar, que se estendiam desde a região dorsal até a região ventral do bulbo (ALEXANDER, 1946; WANG; RANSON, 1939). A ideia de um centro vasomotor simpático com localização delimitada, como proposto por Dittmar passou então a ser desacreditada. Os dados obtidos utilizando a técnica de estimulação elétrica, que reconhecidamente interfere não só sobre os corpos celulares dos neurônios, como também sobre fibras de passagem, não permitia delimitar com exatidão a localização das regiões envolvidas no controle cardiovascular.

Entretanto, os estudos de Feldberg e Guertzenstein (1972) e Guertzenstein (1973) foram os primeiros a demonstrar a existência da atividade tônica de neurônios localizados na superfície ventral do bulbo rostral de gatos sobre a manutenção da pressão arterial. Inicialmente, eles demonstraram que a administração intracerebroventricular de pentobarbital sódico produzia queda da pressão arterial; a mesma dose administrada intravenosamente ou quando o aqueduto cerebral que liga o terceiro ao quarto ventrículo era obstruído, a hipotensão desaparecia, sugerindo que o pentobarbital atuava na região bulbar (FELDBERG; GUERTZENSTEIN, 1972). Os autores também utilizaram-se de drogas que agem preferencialmente em corpos celulares, como o ácido gamaaminobutírico (GABA) e a glicina que ao serem aplicados localmente sobre a região estudada (superfície rostral do bulbo ventrolateral), produziam acentuada queda da pressão arterial. Com tais experimentos, foi possível localizar mais precisamente a região ventrolateral do bulbo responsável pela manutenção da pressão arterial. Novamente, o conceito de um centro vasomotor delimitado voltou a ser considerada.

A partir das publicações de Guertzenstein e colaboradores (1972, 1973, 1974, 1976, 1984), diferentes grupos de pesquisa começaram a se dedicar na tentativa de 
melhor compreender a participação do bulbo ventrolateral no controle cardiovascular. Os estudos foram sendo realizados para elucidar a contribuição no bulbo ventrolateral não somente na manutenção do tônus vasomotor simpático, mas também no que diz respeito ao seu papel no controle reflexo cardiovascular e ajustes cardiovasculares específicos, como durante o exercício, o estresse e integrações com outros sistemas biológicos (GUYENET, 2006).

Até então, ou seja, em meados da década de 70, o núcleo do trato solitário (NTS) localizado na região dorsal do bulbo era conhecido como o maior centro integrador cardiovascular, particularmente por receber as informações dos aferentes barorreceptores. Outra região considerada importante era a coluna intermédio-lateral (IML) da medula espinal, pois era sabido que esta região contém os neurônios préganglionares simpáticos. No entanto, o centro responsável pela conexão NTS-IML, ou seja, o centro vasomotor tinha localização indefinida (CHALMERS; PILOWSKY, 1991). Dessa forma, sobretudo os estudos de Guertzenstein e colaboradores foram fundamentais no sentido de delimitar um centro vasomotor simpático integrador localizado no bulbo ventrolateral rostral (RVL) e de fundamental importância para manutenção da homeostase cardiovascular.

Atualmente sabe-se que o bulbo participa no controle cardiovascular, gerando sinais que são continuamente modulados pelas informações aferentes cardiovasculares (GUYENET, 2006; SPYER, 1990a; SPYER et al., 1990b). O nervo depressor aórtico e do seio carotídeo, cujas aferências têm acesso ao SNC via projeções dos nervos vago e glossofaríngeo são responsáveis pela condução das informações aferentes dos barorreceptores, quimiorreceptores e receptores cardiopulmonares para o SNC, mais precisamente no bulbo, como parte integrante na regulação cardiovascular. Os corpos celulares destas fibras vagais e glossofaríngeas estão localizados nos gânglios nodoso e petroso, respectivamente, tendo suas terminações em neurônios de segunda ordem no NTS (PALKOVITS; ZARBORSKY, 1977).

\subsection{Centro de integração de aferências cardiovasculares: núcleo do trato solitário}

A primeira sinapse ou o sítio de terminação das fibras aferentes no NTS já foi investigado anatômica (COTTLE, 1964; PALKOVITS; ZARBORSKY, 1977; TORVIK, 
1956) e eletrofisiologicamente (FUSSEY et al., 1967; JORDAN; SPYER, 1977; 1978), bem como a expressão da proteína Fos em neurônios do NTS, após a estimulação dos barorreceptores e dos quimiorreceptores (CRUZ et al., 2010; ERICKSON; MILLHORN, 1991; WESTON et al., 2003) em várias espécies.

O NTS é constituído por grupos heterogêneos de neurônios, que estão dispostos dorsalmente no bulbo e se estendem de forma rostrocaudal, como uma coluna bilateral, desde o nível do pólo caudal do núcleo motor do nervo facial até o óbex, onde as duas colunas se unem para formar uma única estrutura na linha média, que continua caudalmente até a parte caudal da decussação piramidal (CIRIELLO et al., 1994; TER HORST; STREEFLAND, 1994).

Em relação ao seu aspecto ântero-posterior, o NTS pode ser dividido em três (3) porções, dada a sua proximidade com a área postrema (COTTLE, 1964; LOEWY, 1990): NTS rostral; NTS intermediário (medial e lateral) e NTS caudal (Fig. 1).

Figura 1- Subdivisão do NTS.

A

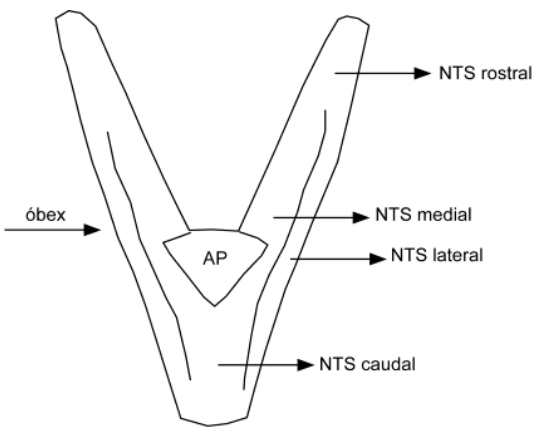

B

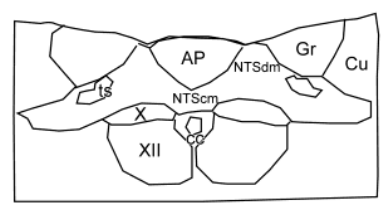

A) subdivisão do NTS em relação à proximidade com área postrema. B) representação de um corte transversal do bulbo do rato, mostrando a localização do NTS em relação a outros núcleos, como área postrema, núcleo grácil, núcleo cuneato, núcleo dorsal motor do vago , núcleo hipoglosso e canal central. Abreviações AP, como área postrema; GR, núcleo grácil; $\mathrm{Cu}$, núcleo cuneato; $\mathrm{cc}$, canal central; NTS, núcleo do trato solitário, TS, trato solitário; XII, núcleo motor do hipoglosso; $X$ núcleo motor do vago.

Fonte: Extraído e adaptado de Ter Horst e Streefland, 1994.

O NTS intermediário e comissural estão diretamente envolvidos no controle cardiovascular e respiratório, pois todas as projeções aferentes vagais e glossofaríngeas, que conduzem informações cardiorrespiratórias, fazem sua primeira sinapse nessas duas porções do NTS. 
Sabe-se que a porção intermediária do NTS constitui o principal sítio de entrada das aferências dos barorreceptores, utilizando o aminoácido excitatório Lglutamato como principal neurotransmissor (TALMAN et al., 1980; WESTON et al., 2003). Já a porção comissural do NTS constitui o principal sítio no SNC para o qual se projetam as aferências dos quimiorreceptores carotídeos (CHITRAVANSHI et al., 1993; CIRIELLO et al., 1994; FINLEY; KATZ, 1992). Curiosamente, a injeção de Lglutamato no NTS intermediário, em animais não anestesiados, promoveu resposta pressora (COLOMBARI et al., 1994; MACHADO; BONAGAMBA, 1992), diferentemente da resposta hipotensora produzida pela estimulação dos barorreceptores (MACHADO; BONAGAMBA, 1992; OHTA; TALMAN, 1994; TALMAN et al., 1980). Como a resposta produzida pela injeção de L-glutamato no NTS intermediário é semelhante à resposta produzida pela ativação dos quimiorreceptores, uma possibilidade seria que o efeito da injeção de L-glutamato no NTS mimetizasse a ativação do quimiorreflexo (HAIBARA et al., 1995). Em animais normotensos, a lesão ou a inibição dos neurônios do NTS comissural bloqueou a resposta pressora do L-glutamato injetado no NTS intermediário e a resposta pressora produzida pela estimulação dos quimiorreceptores periféricos com cianeto de potássio (KCN) ou hipóxia $\left(8 \% \mathrm{O}_{2}\right)$ (COLOMBARI et al., 1996; MOREIRA et al., 2006). Esses resultados levaram à sugestão de que o NTS comissural possui importante participação na ativação do sistema nervoso autônomo simpático.

A partir do NTS, as informações provenientes dos receptores periféricos podem ser distribuídas para diversas áreas do sistema nervoso, dentre as quais se destacam as áreas localizadas na região ventrolateral do bulbo que controlam o tônus simpático sobre o sistema cardiovascular.

\subsection{Mecanismos adrenérgicos no controle da pressão arterial}

Os estudos de Guertzenstein e Silver (1974) demonstraram que manipulações (lesões ou inibições) na superfície ventral do bulbo promoviam grandes alterações na pressão arterial basal. A partir de então, vários estudos mostraram que essa região específica seria a responsável pela manutenção do tônus simpático vasomotor. Além disso, estudos de Ross e colaboradores (1984) utilizando métodos imunoistoquímicos sugeriram que os neurônios geradores da atividade simpática seriam adrenérgicos. Nesse estudo, observou-se uma intensa 
imunorreatividade a feniletolamina-N-metil-tranferase, uma enzima responsável pela síntese de adrenalina numa região localizada na superfície ventral do bulbo. Essa região foi denominada área C1 (ROSS et al., 1984; SCHREIHOFER; GUYENET, 1997).

Atualmente, a área C1 constitui parte da região rostroventrolateral do bulbo (RVL) onde estão localizados os neurônios vasomotores simpáticos. A área C1 contém neurônios catecolaminérgicos, mas também é capaz de liberar o L-glutamato como neurotransmissor e outros neuropeptídeos (SCHREIHOFER; GUYENET, 1997; STORNETTA et al., 2004). Assim, fica claro que esses neurônios apresentam um papel importante no controle da pressão arterial em ratos.

Uma grande expressão de receptores adrenérgicos também foi encontrada na região do NTS (BHUIYAN et al., 2009; LORENZ et al., 1990). Estudos de imunoistoquímica detectaram a presença dos receptores de subtipos $\alpha_{1}$ e $\alpha_{2}$ distribuídos por todo NTS, entretanto, os subtipos $\alpha_{1}$ foram encontrados predominantemente em neurônios ao passo que os subtipos $\alpha_{2}$ foram encontrados predominantemente em astrócitos (BHUIYAN et al., 2009).

Dentre as diversas classes de drogas de ação anti-hipertensiva utilizadas na clínica médica, os agonistas adrenérgicos $\alpha_{2} /$ imidazólicos são uma opção (SICA, 2007; SZABO, 2002). Dentro dessa classe de drogas, as mais utilizadas e estudadas são a clonidina, a moxonidina e a rilmenidina. Estudo comparativo placebo-controle demonstrou que esses fármacos possuem eficácia antihipertensiva semelhante e não provocam efeito significativo na freqüência cardíaca. Entretanto, a moxonidina e a rilmenidina apresentaram menor freqüência de efeitos adversos e não induziu efeito hipertensivo rebote, nem sedação, observados nos pacientes tratados com clonidina (MITROVIC et al., 1991; PLANITZ, 1984). Várias evidências têm sugerido que o efeito anti-hipertensivo desses fármacos é mediado, pelo menos em parte, pela ativação de receptores imidazólicos do tipo 11 presentes na região do RVL que, quando ativados, diminuiriam a atividade neuronal dessa região, reduzindo a atividade eferente simpática e, conseqüentemente, a pressão arterial (BUCCAFUSCO et al., 1995; CHAN; HEAD, 1996; ERNSBERGER et al., 1993, 1994). Os mecanismos neurais promovendo redução da atividade simpática eferente produzida pelos agonistas adrenérgicos $\alpha_{2}$ e imidazólicos são suportados em 2 hipóteses: a primeira seria a chamada hipótese $\alpha_{2}$ e a segunda chamada de hipótese imidazólica. 


\subsection{Principais teorias envolvidas nos mecanismos neurais de fármacos anti- hipertensivos de ação central: hipótese adrenérgica $\alpha_{2} X$ hipótese imidazólico}

A primeira teoria demonstra que os efeitos cardiovasculares, bem como os efeitos sedativos e de redução da secreção salivar, mediados pela clonidina ou moxonidina são dependentes de receptores adrenérgicos $\alpha_{2}$ localizados no SNC, em especial no bulbo ventrolateral (GUYENET, 1997; MOREIRA et al., 2003, 2007). Essa teoria foi a primeira que buscou identificar os mecanismos neurais responsáveis pelos efeitos cardiovasculares dos fármacos anti-hipertensivos de ação central. Na literatura, essa teoria ainda é muito bem aceita e esta baseada em diversos protocolos experimentais (GUYENET, 1997).

Por outro lado, a teoria imidazólica discute que a ativação dos receptores imidazólicos do tipo 11, no bulbo ventrolateral rostral, seriam os principais responsáveis pelos efeitos cardiovasculares da moxonidina, rilmenidina e da clonidina. O principal argumento da teoria imidazólica é que os fármacos adrenérgicas $\alpha_{2}$, sem nenhuma afinidade por receptores imidazólicos, não apresentam respostas hipotensoras e simpatoinibitórias quando injetada no bulbo ventrolateral rostral. Por outro lado, drogas sem afinidade para receptores adrenérgicos $\alpha_{2}$, mas com afinidade para receptores imidazólicos 11 reduzem a pressão arterial (ARMAH, 1998). Outra evidência é que os antagonistas com afinidade imidazólica bloqueiam os efeitos cardiovasculares de agonistas imidazólicos mais efetivamente do que os antagonistas adrenérgicos $\alpha_{2}$ (ARMAH et al., 1998). Os efeitos sedativos e de redução da secreção salivar são dependentes da ativação de receptores adrenérgicos $\alpha_{2}$ e não dos receptores imidazólicos 11 (ERNESBERGER et al., 1997; REIS et al., 1997). Várias evidências da literatura procuraram mostrar que a rilmenidina e a moxonidina não apresentavam os efeitos sedativos indesejáveis dessa classe de medicamentos. Com isso, chegou-se a conclusão que essas drogas tinham preferência para os receptores imidazólicos em relação aos receptores adrenérgicos $\alpha_{2}$. Entretanto, trabalhos da literatura mostraram que a moxonidina apresenta seus efeitos cardiovasculares e de redução da secreção salivar dependentes de receptores adrenérgicos $\alpha_{2}$ (MOREIRA et al., 2001, 2003, 2007; TAKAKURA et al., 2003, 2009). 
Dessa maneira, várias são as controvérsias existentes na literatura sobre a real contribuição dos receptores adrenérgicos $\alpha_{2}$ e imidazólicos no controle da pressão arterial e atividade simpática. Com isso, um dos objetivos do presente estudo foi investigar o envolvimento da moxonidina nas respostas cardiovasculares produzidas pela ativação de receptores adrenérgicos $\alpha_{2}$ na região bulbar, envolvendo duas regiões importantes de controle cardiovascular: o núcleo do trato solitário e a região do bulbo ventrolateral rostral. 


\section{HIPÓTESE}

Como descrito anteriormente, a moxonidina é um fármaco classificado como um anti-hipertensivo de ação central e tem sua ação preferencialmente na região bulbar, mais especificamente na região do $\mathrm{RVL} / \mathrm{C} 1$, reduzindo a atividade simpática eferente. Nossa principal hipótese é que a moxonidina produz suas respostas antihipertensivas (redução da atividade simpática e pressão arterial) atuando também em outra importante estrutura bulbar, o núcleo do trato solitário. Para isso, no presente estudo utilizamos diversos protocolos experimentais para elucidar nossa principal hipótese. 


\section{OBJETIVOS}

Diante das informações que foram discutidas acima, os principais objetivos explorados no presente estudo foram:

1) Avaliar os efeitos da injeção central (4º ventrículo encefálico) de moxonidina em ratos com lesão eletrolítica da região comissural do NTS em ratos não anestesiados.

2) Avaliar os efeitos cardiovasculares e na atividade simpática eferente produzidos pela injeção de moxonidina na região do NTScom em ratos não anestesiados e anestesiados.

3) Avaliar a participação dos receptores adrenérgicos $\alpha_{2}$ nas respostas de hipotensão e simpatoinibição produzidas pela injeção de moxonidina no NTScom em ratos anestesiados.

4) Avaliar os efeitos cardiovasculares e na atividade simpática eferente produzida pela injeção de moxonidina na região do RVL/C1 em ratos anestesiados.

5) Avaliar os efeitos produzidos pela injeção de moxonidina no NTScom na atividade dos neurônios catecolaminérgicos e não catecolaminérgicos da região do RVL/C1. 


\section{MATERIAIS E MÉTODOS}

\subsection{Animais}

Foram utilizados ratos normotensos Wistar, adultos, com peso variando entre 250 e 300 gramas $(N=152)$, procedentes do Biotério de Criação do Departamento de Fisiologia do Instituto de Ciências Biomédicas (ICB) da Universidade de São Paulo. Os animais foram mantidos em caixas individuais com água e ração (Nuvlab) ad libitum. A temperatura e umidade do biotério foram regularmente controladas. $\mathrm{O}$ ciclo claro-escuro do biotério foi mantido como de 12 horas cada. Os protocolos experimentais estão de acordo com os Princípios Éticos de Experimentação Animal adotado pelo Colégio Brasileiro de Experimentação Animal (COBEA) e foram aprovados pela Comissão de Ética no Uso de Animais (CEUA) do ICB-USP em 20 de agosto de 2010, registrado sob ํㅡ 85, na fl. 90, do livro 02 .

Em todos os procedimentos cirúrgicos foram utilizados métodos assépticos para evitar os riscos de infecções.

\subsection{Lesão eletrolítica no núcleo do trato solitário comissural}

Os animais foram anestesiados intraperitonelamente com quetamina (80 $\mathrm{mg} / \mathrm{kg}$ ) + xilazina $(7 \mathrm{mg} / \mathrm{kg}$ ) e adaptados a um aparelho estereotáxico (modelo Kopf 900 ou 1760). Os músculos do pescoço foram descolados do osso occipital e foi realizada uma incisão longitudinal na parte média desses músculos. O osso occipital foi parcialmente removido com auxílio de um osteóstomo de forma a se obter uma boa exposição da superfície do tronco encefálico. Após incisão da dura-máter e aracnóide, um eletrodo de tungstênio de $0,2 \mathrm{~mm}$ de espessura, isolado em toda a sua extensão, exceto $0,5 \mathrm{~mm}$ da extremidade, foi introduzido no encéfalo nas posições de 0,3 $\mathrm{mm}$ caudal ao calamus scriptorius, na linha média e numa profundidade de $0,4 \mathrm{~mm}$ abaixo da superfície dorsal do tronco encefálico. A lesão foi feita pela passagem de uma corrente elétrica de $2 \mathrm{~mA}$ durante 10 segundos. Animais controles foram submetidos à lesão fictícia do NTScom, ou seja, foram submetidos aos mesmos procedimentos cirúrgicos, exceto que não foi feita a passagem de corrente elétrica. No final da cirurgia, os músculos do pescoço foram suturados firmemente e os animais receberam o implante de cânulas cerebrais em 
direção ao quarto ventrículo encefálico.

\subsection{Implante de cânulas encefálicas}

Os animais foram anestesiados intraperitonealmente com quetamina (80 $\mathrm{mg} / \mathrm{kg}$ ) + xilazina $(7 \mathrm{mg} / \mathrm{kg}$ ) e adaptados a um aparelho estereotáxico (modelo Kopf 900 ou 1760). O lambda e o bregma foram utilizados como referência para nivelar as cabeças dos animais. Utilizando-se o bregma para determinar os pontos de introdução da cânula de aço inoxidável nas cabeças dos animais. Nesse ponto foi feita uma trepanação do osso do crânio com uma broca esférica.

Para a região do quarto ventrículo encefálico (4ํV), a cânula foi posicionada 13,3 mm caudal ao lambda, na linha média e 6,5 mm abaixo da superfície da duramater. Para a região do núcleo do trato solitário comissural (NTScom), a cânula foi posicionada 15,0 $\mathrm{mm}$ caudal ao bregma, na linha média e 7,5 $\mathrm{mm}$ abaixo da superfície do osso. As cânulas foram fixadas nas cabeças dos ratos com resina acrílica presa a dois parafusos presos na calota craniana.

Após a cirurgia cerebral, os ratos receberam uma injeção intramuscular $(0,2$ $\mathrm{ml} /$ rato) de Pentabiótico Veterinário - Pequeno Porte (Fort Dodge Saúde Animal Ltda.) e do analgésico/anti-inflamatório Ketoflex (cetoprofeno 1\%, 0,03 ml/rato).

\subsection{Registro da pressão arterial e da frequência cardíaca}

Para registros das variáveis cardiovasculares, os animais foram submetidos a uma canulação da artéria femoral com tubo de polietileno (PE-10 conectado a um PE-50) para o registro da pressão arterial média (PAM) e frequência cardíaca (FC). A cânula da artéria femoral foi conectada a um transdutor de pressão (Physiological Pressure Transducer mod. MLT844, ADInstruments) acoplado a um pré-amplificador (Bridge Bio Amplifier mod. ML221, ADInstruments) e ao sistema de registro computadorizado da Cambridge Electronics Design (CED, Cambridge, UK) de 8 canais. Foram registrados, simultaneamente, a pressão arterial pulsátil (PAP), PAM e FC.

Os animais tiveram a veia femoral canulada com tubo de polietileno (PE-10 conectado a um PE-50) para a infusão de drogas sistêmicas. 


\subsection{Procedimentos cirúrgicos e anestésicos: experimentos em animais anestesiados}

Os animais foram inicialmente anestesiados com halotano 5\% em $100 \%$ de oxigênio. Os animais foram, posteriormente, traqueostomizados e colocados em ventilação artificial com 1,4 - 1,5\% de halotano em $100 \%$ de oxigênio para continuação dos procedimentos cirúrgicos. Em todos os experimentos foram realizados os seguintes procedimentos cirúrgicos:

- canulação da artéria femoral para registro da PAM e FC e canulação da veia femoral para administração de drogas. Em alguns animais $(n=6)$, foi realizada a canulação da artéria e veia braquial para permitir o uso de um oclusor colocado ao redor da artéria aorta torácica, permitindo assim a ativação e desativação dos barorreceptores.

- $\quad$ colocados em um aparelho estereotáxico (modelo Kopf 1760, David Kopf Instruments, USA);

- a remoção do osso occipital e de retração da dura-máter subjacente para a inserção de uma pipeta de vidro para injeção no bulbo via uma abordagem transcerebelar (TAKAKURA; MOREIRA, 2011);

- a localização e exposição do nervo esplâncnico via posição dorsolateral, (MOREIRA et al., 2006; TAKAKURA et al., 2011; TAKAKURA; MOREIRA, 2011).

Após a finalização dos procedimentos cirúrgicos, o anestésico halotano foi substituído pelo anestésico endovenoso uretana $(1,2 \mathrm{~g} / \mathrm{kg})$.

Todos os animais foram ventilados (60-80 ciclos; $1,2 \mathrm{ml} / \mathrm{kg}$ ) com $100 \%$ de oxigênio durante todo o período experimental. Os animais receberam uma sonda retal para monitorização da temperatura corporal e sua temperatura foi mantida em $37^{\circ} \mathrm{C}$, utilizando-se um colchão com resistência interna para aquecimento. $\mathrm{O}$ índice de $\mathrm{CO}_{2}$-expirado foi monitorado durante todo o experimento por meio de um capnômetro (Columbus Instruments, Ohio, USA). O nível da anestesia foi sempre monitorado testando-se a ausência de efeitos no reflexo de retirada e ausências de mudanças na pressão arterial após o pinçamento da pata do animal. Satisfeito esses critérios, o relaxante muscular (pancurônio) foi administrado endovenosamente com uma dose inicial de $1 \mathrm{mg} / \mathrm{kg}$. 


\subsection{Medida da atividade do nervo esplâncnico}

Por meio de um modelo de abertura retroperitoneal, o nervo esplâncnico direito foi exposto na saída do gânglio supra-renal. A atividade simpática pósganglionar do nervo esplâncnico foi registrada utilizando-se um eletrodo bipolar em forma de gancho em configuração monopolar. A atividade simpática do nervo esplâncnico foi amplificada em 20.000 vezes e filtrada de 100 a $3000 \mathrm{~Hz}$.

Os nervos e o eletrodo de registro foram cobertos com uma pasta de moldagem dental (Kwik-Cast Sealant, WPI, USP).

O eletrodo bipolar em que os nervos foram colocados foi conectado a um conversor analógico-digital (modelo CED-1401) da Cambridge Electronics Design (CED, Cambridge, UK) de 8 canais. Este aparelho possui filtro passa-baixo, ligação AC-DC (corrente direta-alternada), filtro de corte, permite variação do ganho e possibilita correção da linha de base. A partir deste aparelho, o sinal foi copiado para um sistema de aquisição de dados versão 6 do Spike 2 software (CED). Os resultados foram gravados em DVD para posterior análise dos resultados.

\subsection{Registro extracelular dos neurônios do RVL}

Os animais foram colocados em aparelho estereotáxico, sua cabeça foi fixada por meio de duas barras auriculares e posteriormente nivelada (as suturas bregma e lâmbda da calota craniana devem ficar no mesmo nível horizontal). Após este procedimento, foi feita uma incisão longitudinal na pele da cabeça e tecido subcutâneo. Os ossos do crânio foram expostos, sendo utilizada solução fisiológica para limpeza da área. Foi feita uma trepanação do osso do crânio (região do osso occipital) com uma broca esférica, abrindo-se uma cavidade para inserção do eletrodo de registro.

As coordenadas para registro dos neurônios da região do RVL seguiram os seguintes procedimentos: primeiramente, foi identificado o potencial antidrômico do núcleo facial (Fig. 2). 
Figura 2- Registro extracelular dos neurônios do RVL.

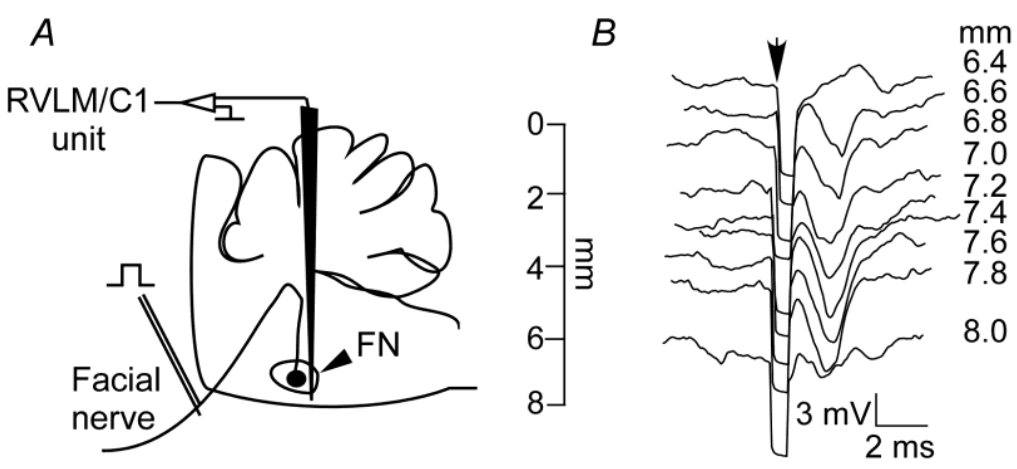

A) registro dos neurônios da região do RVL/C1 foram realizados em proximidade como o núcleo motor facial. B) exemplo de potenciais antidrômicos do núcleo motor facial a medida que a pipeta de registro adentrava no bulbo.

O limite caudal e ventral do núcleo motor do facial foi identificado por um elevado potencial antidrômico negativo (mais de $5 \mathrm{mV}$ ) gerado no núcleo facial, a partir da estimulação do ramo mandibular do nervo facial (BROWN; GUYENET, 1985) (Fig. 2). A atividade dos potencias de ação dos neurônios foram registrados extracelularmente através de uma pipeta de vidro preenchida com solução de 0,5 M de acetato de sódio contendo $1,5 \%$ de biotinamida (Molecular Probes, www.molecularprobes.com). A resistência dos eletrodos para registro foi em torno de 20 a $40 \mathrm{M} \Omega$. Os registros foram realizados com um amplificador intracelular (AMSystem Intracelular Amplifier 1600) para permitir o monitoramento dos potencias de ação durante a injeção de corrente no neurônio para a realização de sua marcação. Diante disso, para os registros dos neurônios simpáticos do RVL foram utilizadas as seguintes coordenadas: 100-200 $\mu \mathrm{m}$ ventral à superfície ventral do núcleo facial, 1,6$1,9 \mathrm{~mm}$ lateral em relação à linha média e $0-400 \mu \mathrm{m}$ caudal em relação à porção caudal do núcleo facial. Os neurônios do RVL selecionados para registro e identificação seguiram as seguintes características: localização abaixo e caudal à porção caudal do núcleo facial; atividade espontânea, projeções para a coluna intermédio-lateral (teste de colisão) e modulação com o pulso de pressão arterial. Após a identificação dos neurônios do RVL, estes foram marcados com biotinamida segundo a técnica de marcação justacelular (passagem de corrente através do eletrodo e injeção do marcador: $200 \mathrm{~ms}, 1$ a $4 \mathrm{nA}, 2,5 \mathrm{~Hz}$ durante 1 a 3 minutos) (PINAULT, 1996; SCHREIHOFER; GUYENET 1997) e detecção imunoistoquímica 
para tirosina hidroxilase $(\mathrm{TH})$.

\subsection{Injeções cerebrais}

As injeções no $4^{\circ} \mathrm{V}$ ou no NTScom dos ratos não anestesiados foram realizadas com uma seringa Hamilton (1 ou $5 \mu \mathrm{l}$ ), conectada por um tubo de polietileno PE-10 a uma agulha injetora que foi introduzida no encéfalo pela cânula guia previamente fixada no encéfalo. A cânula injetora foi 2,0 $\mathrm{mm}$ mais longa do que a cânula guia. O volume de injeção foi de $1 \mu \mathrm{l}$ para o $4^{\circ} \mathrm{V}$ e de $50 \mathrm{nl}$ no NTScom.

As injeções de drogas na região do NTScom ou, na região RVL/C1, em animais anestesiados foram realizadas sob pressão com nitrogênio, utilizando-se pipetas de vidro (diâmetro interno $25 \mu \mathrm{m}$, Sutter Instrument Co, CA) acopladas ao aparelho PicoSpritzer III (General Valve Corporation, NJ). O volume das injeções no NTScom e no RVL/C1 foi de $50 \mathrm{nl}$ em cada lado (injeções bilaterais para o RVL/C1).

As coordenadas utilizadas para atingir o NTScom foram baseadas em relação ao calamus scriptorius (MOREIRA et al., 2005; 2006). As injeções foram realizadas $300 \mu \mathrm{m}$ caudal ao calamus scriptorius, na linha média e $400 \mu \mathrm{m}$ ventral em relação à superfície do bulbo. As coordenadas utilizadas para atingir o RVL/C1 foram baseadas no potencial antidrômico do núcleo facial (BROWN; GUYENET, 1985; LIPSKI, 1981). As injeções foram realizadas 100 a $400 \mu \mathrm{m}$ caudal a porção final do núcleo facial, 1,6 a 1,9 mm lateral a linha média e $200 \mu \mathrm{m}$ ventral ao limite ventral do potencial antidrômico do núcleo facial. Os registros eletrofisiológicos foram realizados em um lado e a segunda injeção foi realizada simetricamente do outro lado baseado nas coordenadas estereotáxicas da primeira injeção.

\subsection{Drogas utilizadas}

As drogas utilizadas foram:

- $\quad$ Cloridrato de moxonidina (doação da Solvay Pharma, Hannover, Alemanha) (agonista de receptores adrenérgicos $\alpha_{2}$ e imidazólicos): 1; 2,5 e 5 $\mathrm{nmol} / 50 \mathrm{nl}$ no NTScom e RVL/C1. As injeções no 4ํㅡ $\mathrm{V}$ foram de $20 \mathrm{nmol} / 1 \mu \mathrm{l}$.

- $\quad$ Cloridrato de ioimbina (Sigma-Aldrich, MO, USA) (antagonista de receptores adrenérgicos $\alpha_{2}$ ): $10 \mathrm{nmol} / 50 \mathrm{nl}$ para injeções no NTScom.

- $\quad \mathrm{RX821002}$ (Sigma-Aldrich, MO, USA) (antagonista de receptores 
adrenérgicos $\alpha_{2}$ ): $10 \mathrm{nmol} / 50 \mathrm{nl}$ para injeções no NTScom.

- Cloridrato de fenilefrina (agonista adrenérgico $\alpha_{1}$ ): $5 \mu \mathrm{g} / \mathrm{kg}$ de peso corporal.

- $\quad$ Nitroprussiato de sódio (doador de óxido nítrico): $30 \mu \mathrm{g} / \mathrm{kg}$ de peso corporal.

- $\quad$ Cianeto de potássio: $40 \mu \mathrm{g} / 0,1 \mathrm{ml}$ por animal.

- Cloridrato de hexametônio: $30 \mathrm{mg} / \mathrm{kg}$ de peso corporal

Cloridrato de fenilefrina e nitroprussiato de sódio foram injetados intravenosamente (i.v) para se avaliar a funcionalidade do barorreflexo. Cianeto de potássio foi injetado i.v para testar a funcionalidade do quimiorreflexo periférico. Cloridrato de hexametônio foi injetado i.v para bloquear a atividade ganglionar simpática ao final dos experimentos em animais anestesiados. As doses utilizadas foram baseadas em trabalhos anteriores que mostraram os efeitos da moxonidina $e$ dos antagonistas adrenérgicos $\alpha_{2}$ em áreas encefálicas (ANDRADE et al., 2004; MOREIRA et al., 2004, 2007).

\subsection{Histologia}

Ao término dos experimentos, os animais foram profundamente anestesiados com pentobarbital de sódio $(60 \mathrm{mg} / \mathrm{kg})$ e perfundidos através do ventrículo cardíaco esquerdo com PBS ( $\mathrm{pH} 7,4)$ seguido de paraformaldeído (4\% em 0,1 M de fosfato, $\mathrm{pH} 7,4)$. Os encéfalos foram retirados e guardados nesse fixador por 24 horas a $4^{\circ} \mathrm{C}$. Os encéfalos foram cortados em micrótomo numa espessura de $40 \mu \mathrm{m}$, corados pelo método de Tionina e analisados ao microscópio para localização das injeções encefálicas. Apenas os animais com injeção nas áreas pré-determinadas tiveram os resultados analisados.

No grupo de animais em que foi feito o registro dos neurônios do RVL, após realizado os cortes dos encéfalos, estes foram guardados em solução crioprotetora (20\% de glicerol, $30 \%$ de etileno glicol em 50 mM de fostato, $\mathrm{pH} 7.4$ ) que preserva as qualidades do tecido encefálico para posterior tratamento imunoistoquímico (Schreihofer; Guyenet, 1997). Os cortes encefálicos foram processados para visualização do marcador biotinamida e TH. Biotinamida foi revelada incubando-se as secções em streptavidina no conjugado Alexa 488 (1:200; 3h; Jackson Immunoresearch Laboratories, West Grove, PA). Esse método foi combinado com 
imunofluorescência para detecção de TH usando-se um anticorpo primário (coelho anti-TH; 1:2000) e revelado com Cy3 anti-coelho lgG (1:200; Jackson Immunoresearch Laboratories, West Grove, PA).

Finalmente, os cortes encefálicos foram montados em sequência rostrocaudal em lâminas. Foram desidratados com álcool e xilol e posteriormente cobertos com Krystalon (EMD Chemicals Inc, NJ).

Após finalizado os tratamentos imunoistoquímicos, os cortes encefálicos foram analisados num microscópio (Zeiss Axioskop 2) tanto para conferir os locais das injeções e a localização dos neurônios marcados com a biotinamida, com o fenótipo presente (presença de tirosina hidroxilase). Toda a nomenclatura anatômica foi baseada no atlas de Paxinos e Watson (1998) e em trabalhos anteriores (MOREIRA et al., 2006; TAKAKURA et al., 2006).

\subsection{Análise dos resultados}

Os resultados dos animais com injeções localizadas corretamente nas áreas pré-determinadas foram tabelados e representados em gráficos como média \pm erro padrão da média. Teste T de studente não pareado e Teste de Student-NewmanKeuls precedido de análise de variância de uma ou duas vias foram utilizados para comparação entre as médias mediante a necessidade. O índice de significância foi fixado em $p<0,05$. 


\section{PROTOCOLOS EXPERIMENTAIS}

\subsection{Efeitos cardiovasculares da injeção central (4ำ V) de moxonidina em ratos com lesão eletrolítica da região comissural do NTS}

Os animais passaram por procedimentos cirúrgicos para 0 implante de cânulas de aço inoxidável na região do $4^{\circ}$ V e lesão eletrolítica aguda do NTScom, bem como o implante de cânulas de polietileno na artéria e veia femoral. No dia seguinte a canulação da artéria e veia femoral, os animais foram colocados, individualmente, em uma caixa para registro das variáveis cardiovasculares (pressão arterial e frequência cardíaca). Após as fases exploratórias, que variam entre 30 e 45 minutos, as medidas da PAM e FC basais foram efetuadas por 10 minutos em animais não anestesiados. Após um período controle de registro das variáveis cardiovasculares, foram realizadas injeções de veículo $(1 \mu \mathrm{l})$ ou moxonidina (20 $\mathrm{nmol} / 1 \mu \mathrm{l})$ na região do $4^{\circ} \mathrm{V}$ e foi aguardado um período de 30 minutos. Antes e após as injeções de veículo ou moxonidina no $4^{\circ} \stackrel{\mathrm{V}}{\mathrm{V}}$, foi testado o barorreflexo com injeções i.v de fenilefrina ( $5 \mu \mathrm{g} / \mathrm{kg}$ de peso corporal) e nitroprussiato de sódio (30 $\mu \mathrm{g} / \mathrm{kg}$ de peso corporal). O teste do quimiorreflexo foi realizado com injeções i.v de cianeto de potássio $(40 \mu \mathrm{g} / 0,1 \mathrm{ml})$.

Para motivos de comparação, foi realizado um grupo experimental na qual os animais receberão lesões fictícias na região do NTScom e os mesmos protocolos experimentais, descritos acima, foram executados.

\subsection{Efeitos cardiovasculares produzidos pela injeção de moxonidina na região do NTScom em ratos não anestesiados}

Os animais sofreram os procedimentos cirúrgicos para o implante de cânulas de aço inoxidável na região do NTScom, bem como o implante de cânulas de polietileno na artéria e veia femoral. No dia seguinte a canulação da artéria e veia femoral, os animais foram colocados, individualmente, em uma caixa para registro das variáveis cardiovasculares (PAM e FC). Após as fases exploratórias, que variam entre 30 e 45 minutos, as medidas da PAM e FC basal foram efetuadas em animais não anestesiados. Após um período controle de registro das variáveis cardiovasculares, foram realizadas injeções de veículo (50 nl) no NTScom. Após 30 
minutos, moxonidina $(1 ; 2,5$ e $5 \mathrm{nmol} / 50 \mathrm{nl})$ foi injetada na região do NTScom e foi aguardado um período de 30 minutos. Antes e após as injeções de veículo ou moxonidina no NTScom, foi testado o barorreflexo com injeções i.v de fenilefrina (5 $\mu \mathrm{g} / \mathrm{kg}$ de peso corporal) e nitroprussiato de sódio (30 $\mu \mathrm{g} / \mathrm{kg}$ de peso corporal). $\mathrm{O}$ teste do quimiorreflexo foi realizado com injeções i.v de cianeto de potássio (40 $\mu \mathrm{g} / 0,1 \mathrm{ml})$.

\subsection{Respostas cardiovasculares e de atividade simpática produzidos pela injeção de moxonidina no NTScom ou no RVL/C1 em ratos anestesiados}

Esses experimentos foram realizados em ratos anestesiados com uretana $(1,2 \mathrm{~g} / \mathrm{kg})$, traqueostomizados, ventilados artificialmente $\left(100 \% \mathrm{O}_{2}\right)$, tiveram a artéria e veia femoral canuladas (para registro de PAM, FC e infusão de drogas, respectivamente) e o nervo esplâncnico dissecado para registro da atividade simpática eferente. Após um período controle de registro das variáveis cardiovasculares e simpáticas (10 minutos), foram realizadas injeções de veículo (50 $\mathrm{nl}$ ) ou moxonidina (1, 2,5 e $5 \mathrm{nmol} / 50 \mathrm{nl})$ no NTScom e foi aguardado um período de 60 minutos com análises a cada 10 minutos. Foi realizado um grupo experimental na qual os animais receberam injeções bilaterais de veículo ou moxonidina (1, 2,5 e 5 $\mathrm{nmol} / 50 \mathrm{nl}$ ) na região $\mathrm{RVL}$ e os mesmos protocolos experimentais, descritos acima, foram executados.

\subsection{Participação dos receptores adrenérgicos $\alpha_{2}$ nas respostas de hipotensão e simpatoinibição produzidas pela injeção de moxonidina no NTScom em ratos anestesiados}

Esses experimentos foram realizados em ratos anestesiados com uretana $(1,2 \mathrm{~g} / \mathrm{kg})$, traqueostomizados, ventilados artificialmente $\left(100 \% \mathrm{O}_{2}\right)$, tiveram a artéria e veia femoral canuladas (para registro de PAM e infusão de drogas) e o nervo esplâncnico dissecado para registro da atividade simpática eferente. Após um período controle de registro das variáveis cardiovasculares e simpáticas (10 minutos), foram realizadas injeções de veículo, ioimbina $(10 \mathrm{nmol} / 50 \mathrm{nl})$ ou RX821002 (10 nmol/50 nl) no NTScom, após 10 minutos foi injetado veículo ou moxonidina $(5 \mathrm{nmol} / 50 \mathrm{nl})$ no NTScom e foi aguardado um período de 30 minutos 
com análises a cada 10 minutos.

\subsection{Efeitos produzidos pela injeção de moxonidina no NTScom na atividade elétrica dos neurônios pré-simpáticos da região RVL/C1}

Os experimentos foram realizados em ratos anestesiados com uretana $(1,2$ $\mathrm{g} / \mathrm{kg})$, traqueostomizados, ventilados artificialmente $\left(100 \% \mathrm{O}_{2}\right)$, tiveram a artéria e veia femoral canuladas (para registro de PAM, FC e infusão de drogas, respectivamente) e um eletrodo de registro (pipeta de vidro) da atividade extracelular dos neurônios localizados na região RVL/C1. Após a caracterização dos neurônios pré-simpáticos da região do RVL/C1 (ver métodos para maiores detalhes), foi feito um registro controle das variáveis cardiovasculares e da atividade neuronal e foram realizadas injeções de veículo (50 nl) ou moxonidina (5 nmol/50 nl) no NTScom e foi aguardado um período de 10 minutos. 


\section{RESULTADOS}

\subsection{Efeitos da lesão eletrolítica do NTScom nas respostas cardiovasculares produzidas pela injeção de moxonidina no $4^{\circ} \mathrm{V}$ em ratos não anestesiados}

Podemos observar na fotomicrografia da região dorsal do encéfalo do rato que a lesão eletrolítica ficou restrita apenas na região comissural do NTS, mostrando que a lesão não afetou a área postrema (AP), o canal central (cc) e o núcleo motor do hipoglosso (XII). A extensão das lesões foi semelhante ao observado em estudos prévios, isto é, a lesão da região comissural do NTS, no sentido rostro-caudal, extendeu-se aproximadamente 700-800 $\mu \mathrm{m}$ (COLOMBARI et al., 1996; MOREIRA et al., 2009; SATO et al., 1999) (Fig. 3A) A lesão eletrolítica do NTScom não alterou a PAM basal ( $\Delta=4 \pm 2$, vs. lesão fictícia: $\Delta=2 \pm 2 \mathrm{mmHg}$, p $>0,05)$ e FC basal $(\Delta=9 \pm$ 6, vs. lesão fictícia: $\Delta=11 \pm 4$ bpm, p>0,05 ) (Figs. 3B e 3C).

A injeção do agonista adrenérgico $\alpha_{2}$ e imidazólico moxonidina $(20 \mathrm{nmol} / 1 \mu \mathrm{l})$ no $4^{\circ} \mathrm{V}$ em ratos não anestesiados ( $\mathrm{n}=6$-7/grupo) diminuiu a $\operatorname{PAM}(\Delta=-36 \pm 5$, vs. veículo: $\Delta=2 \pm 2 \mathrm{mmHg}, \mathrm{p}<0,01)$ e FC $(\Delta=-23 \pm 9$, vs. veículo: $\Delta=7 \pm 6 \mathrm{bpm}$, $\mathrm{p}<0,01$ ) (Figs. 3B-3C). A hipotensão promovida pela injeção de moxonidina no $4^{\circ} \mathrm{V}$ foi atenuada após a lesão eletrolítica do NTScom $(\Delta=-14 \pm 3$, vs. lesão fictícia + moxonidina: $\Delta=-36 \pm 5 \mathrm{mmHg})[\mathrm{F}(3,72)=114,16, \mathrm{p}<0,05]$ (Fig. 3B). A bradicardia produzida pela injeção de moxonidina no $4^{\circ} \vee \mathrm{V}$ não foi alterada $(\Delta=-28 \pm 13$, vs lesão fictícia + moxonidina: $\Delta=-23 \pm 9$ bpm) após a lesão do $\operatorname{NTScom~}[F(3,72)=$ 1,22, p>0,05] (Fig. 3C).

A lesão eletrolítica no NTScom não foi capaz de promover alterações nas respostas cardiovasculares promovidas pela ativação e desativação do barorreflexo. Mais precisamente, a lesão do NTScom não alterou a resposta pressora (53 \pm 3 $\mathrm{mmHg}$, vs. lesão fictícia: $65 \pm 2 \mathrm{mmHg}, \mathrm{p}>0,05)$ produzida pela injeção i.v de fenilefrina (5 $\mu \mathrm{g} / \mathrm{kg})$, nem a bradicardia reflexa (-77 $\pm 8 \mathrm{bpm}$, vs. lesão fictícia: $-71 \pm 4$ bpm, p>0,05) (Fig. 4A). Da mesma maneira, a lesão eletrolítica do NTScom não foi capaz de alterar a resposta depressora $(-39 \pm 4 \mathrm{mmHg}$, vs. lesão fictícia: $-29 \pm 2$ $\mathrm{mmHg}, \mathrm{p}>0,05)$ produzida pela injeção i.v de nitroprussiato de sódio (30 $\mu \mathrm{g} / \mathrm{kg}$ ) (Fig. 4A). No entanto, a lesão do NTScom foi capaz de atenuar a taquicardia reflexa (85 \pm 10 bpm, vs. lesão fictícia: $105 \pm 15$ bpm, p>0,05) produzida pela injeção i.v de 
nitroprussiato de sódio (Fig. 4A).

Como esperado, a lesão do NTScom foi capaz de bloquear as respostas pressora ( $6 \pm 2 \mathrm{mmHg}$, vs. sham: $53 \pm 7 \mathrm{mmHg}, p<0,01)$ e bradicárdica $(-20 \pm 12$ bpm, vs. sham: $-89 \pm 17 \mathrm{bpm}, \mathrm{p}<0,01$ ) produzidas pela ativação do quimiorreflexo periférico com a injeção i.v de cianeto de sódio (40 $\mu \mathrm{g} / 0,1 \mathrm{ml})$ (Fig. 4B). 
Figura 3- Injeção de moxonidina no quarto ventrículo em ratos com lesão eletrolítica da região comissural do NTS.
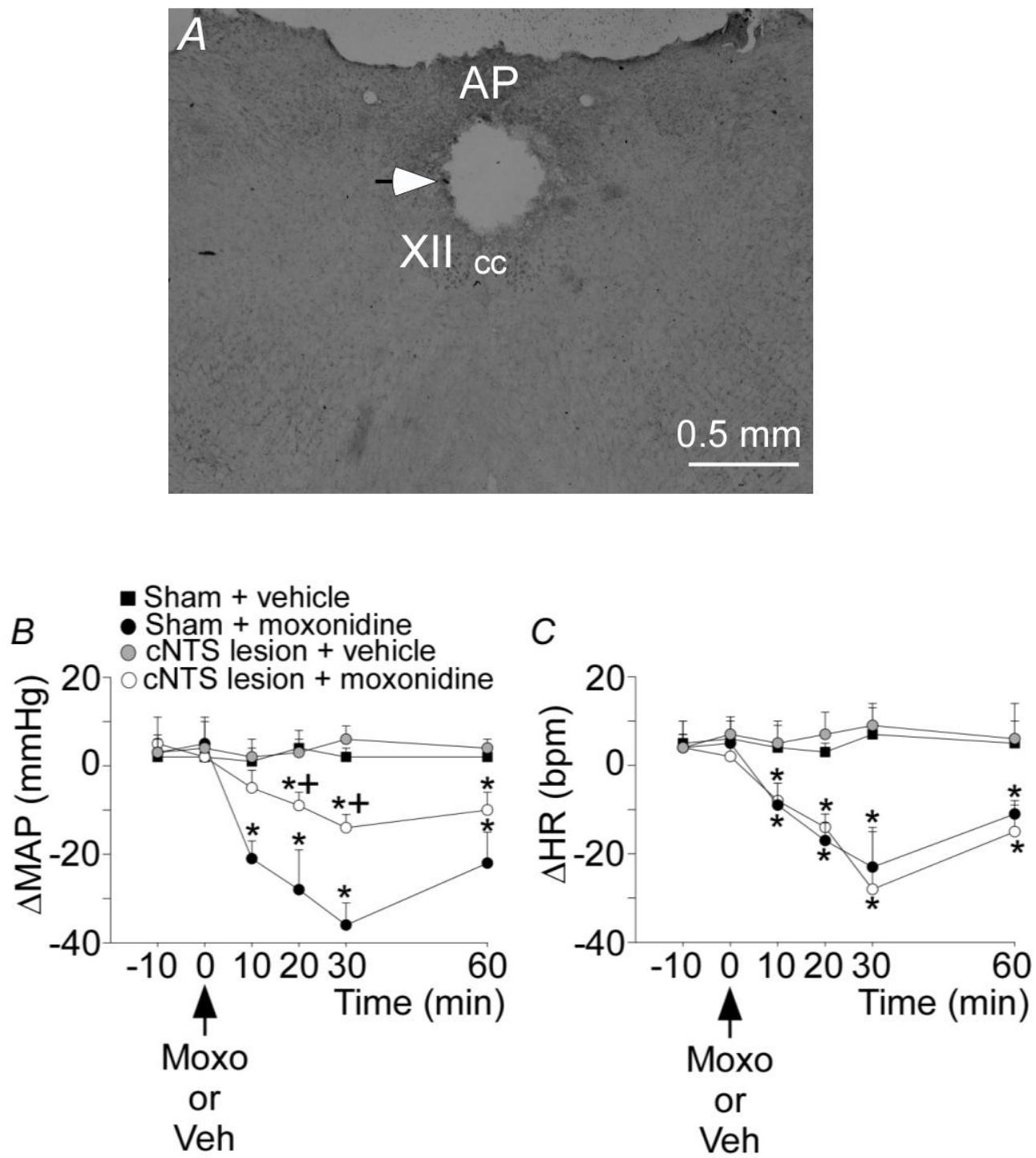

A) A fotomicrografia mostrando a lesão típica (ponta da seta) da região comissural do NTS. A lesão do NTScom extendeu-se por aproximadamente $700-800 \mu \mathrm{m}$ no sentido rostrocaudal. De acordo com o atlas de encéfalo de rato do Paxinos e Watson (1998), as secções extendem-se de valores de Bregma de -13,8 a -14.6 mm. B e C) alterações na pressão arterial média $(\triangle \mathrm{MAP})$ e frequência cardíaca $(\triangle \mathrm{HR})$, respectivamente, produzidos pela injeção de veículo ou moxonidina $(20 \mathrm{nmol} / 1 \mu \mathrm{l})$ no $4^{\circ} \mathrm{V}$ em ratos com lesão fictícia (sham) ou eletrolítica do NTScom. Abreviaturas: AP, área postrema; cc, canal central ; XII, núcleo motor do hipoglosso. Escala $=0,5 \mathrm{~mm}$. Os resultados estão apresentados como média \pm EPM. *Diferente de lesão fictícia + veículo $(p<0,05) ;$ + diferente de lesão fictícia + moxonidina $(p<0,05)$. Análise de variância de duas vias, seguido do teste de StudentNewman-Keuls, $n=6-7 / g r u p o$. 
Figura 4 - Efeitos da lesão eletrolítica do NTScom nas respostas cardiovasculares promovidas pela ativação e desativação do barorreflexo e ativação do quimiorreflexo periférico.

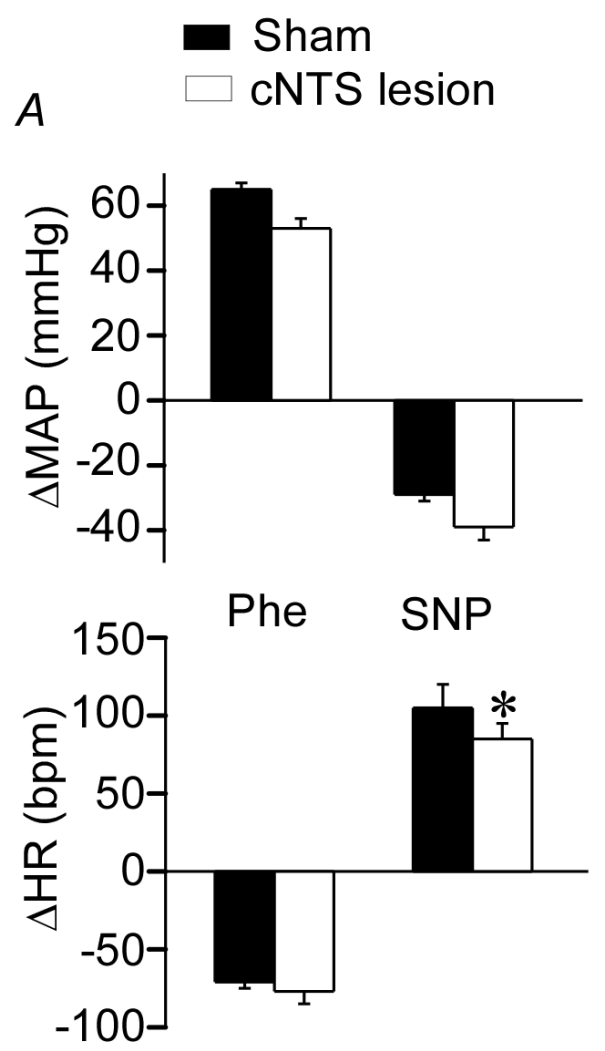

$B$

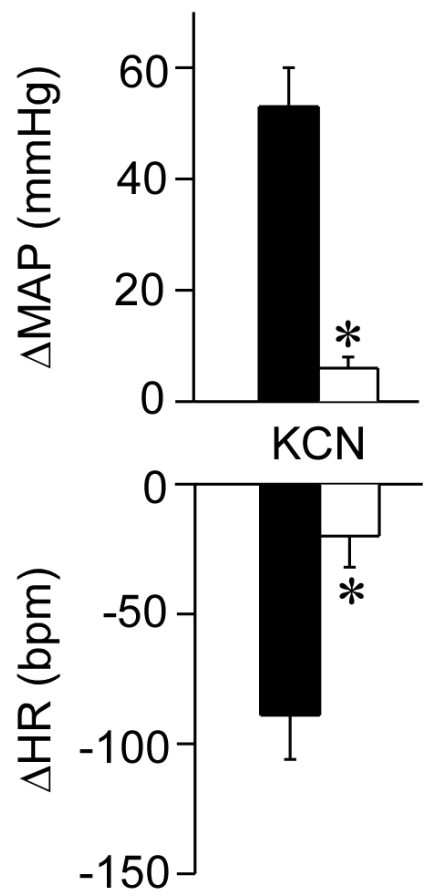

A-B) Alterações na PAM ( $\triangle$ MAP) e FC ( $\Delta \mathrm{HR})$ produzidas pela injeção intravenosa (iv) de fenilefrina (Phe - $5 \mu \mathrm{g} / \mathrm{kg}$ ), nitroprussiato de sódio (SNP - $30 \mu \mathrm{g} / \mathrm{kg}$ ) e cianeto de sódio) (KCN - $40 \mu \mathrm{g} / 0,1 \mathrm{ml}$ ) em animais controle (lesão fictícia (sham)) ou com lesão eletrolítica do NTScom. * Diferente de lesão fictícia $(p<0,05)$. Teste T de student, $n=6-7 / g r u p o$. 


\subsection{Efeitos cardiovasculares promovidos pela injeção de moxonidina no NTScom em ratos não anestesiados}

Os resultados ilustrados acima mostraram que a lesão eletrolítica do NTScom foi capaz de reduzir a hipotensão produzida pela injeção de moxonidina no 4ํ V. Dessa maneira, surgiu a hipótese de que a região comissural do NTS poderia estar envolvida nos efeitos anti-hipertensivos promovidos pela moxonidina. Portanto, o próximo conjunto de resultados foi tentar verificar se a moxonidina poderia estar atuando na região do NTScom.

A figura $5 \mathrm{~A}$ mostra uma fotomicrografia de um corte coronal do encéfalo de rato, ilustrando a injeção de moxonidina no NTScom. As injeções de moxonidina no NTScom foi centrada na linha média, na região do NTScom, aproximadamente 400 $\mu \mathrm{m}$ caudal ao calamus scriptorius (Fig. 5B), como ilustrado nas Figs. 5A e 5B.

Em ratos não anestesiados (PAM basal: $106 \pm 3 \mathrm{mmHg}$ e FC basal: $322 \pm 11$ bpm, $\mathrm{n}=5-7 /$ grupo), as injeções de moxonidina ( $1 ; 2,5$ e $5 \mathrm{nmol} / 50 \mathrm{nl}$ ) no NTScom foi capaz de reduzir a PAM $(\Delta=-7 \pm 3,-17 \pm 6$ e $-28 \pm 4$, vs. veículo: $\Delta=4 \pm 3$ $\mathrm{mmHg})[\mathrm{F}(3,56)=215,22, \mathrm{p}<0,05]$ e $\mathrm{FC}(\Delta=-10 \pm 4,-22 \pm 3$ e $-27 \pm 4$, vs. veículo: $\Delta=5 \pm 2 \mathrm{bpm})[\mathrm{F}(3,56)=98,37, \mathrm{p}<0,05]$ (Figs. $6 \mathrm{~A}$ e $6 \mathrm{~B})$. As injeções de veículo NTScom não foram capazes de alterar a PAM e FC basal (Figs. 6A e 6B).

Os efeitos hipotensores e bradicárdicos produzidos pela moxonidina tiveram uma resposta lenta e foram necessários aproximadamente 10 minutos para iniciar uma redução da PAM e FC, atingindo o pico da resposta aos 30 minutos (Figs. 6A e $6 B)$.

A injeção de moxonidina $(5 \mathrm{nmol} / 50 \mathrm{nl}$ ) no NTScom não foi capaz de promover alterações nas respostas cardiovasculares promovidas pela ativação e desativação do barorreflexo. Moxonidina injetada no NTScom não alterou a resposta pressora ( $55 \pm 9 \mathrm{mmHg}$, vs. veículo: $58 \pm 12 \mathrm{mmHg}, p>0,05$ ) produzida pela injeção i.v de fenilefrina $(5 \mu \mathrm{g} / \mathrm{kg})$, nem a bradicardia reflexa $(-69 \pm 11 \mathrm{bpm}$, vs. veículo: $-65 \pm$ $14 \mathrm{bpm}, \mathrm{p}>0,05)$ (Fig. 7A). Da mesma maneira, moxonidina no NTScom não foi capaz de alterar a resposta depressora $(-35 \pm 9 \mathrm{mmHg}$, vs. veículo: $-33 \pm 8 \mathrm{mmHg}$, $p>0,05)$ produzida pela injeção i.v de nitroprussiato de sódio $(30 \mu \mathrm{g} / \mathrm{kg})$, nem a taquicardia reflexa ( $87 \pm 15 \mathrm{bpm}$, vs. veículo: $94 \pm 21 \mathrm{bpm}, \mathrm{p}>0,05)$ produzida pela injeção i.v de nitroprussiato de sódio (Fig. 7A). 
A injeção de moxonidina no NTScom foi capaz de atenuar as respostas pressora (34 $\pm 6 \mathrm{mmHg}$, vs. veículo: $57 \pm 5 \mathrm{mmHg}, \mathrm{p}<0,05)$ e bradicárdica $(-41 \pm 15$ bpm, vs. veículo: $-86 \pm 9$ bpm, $p<0,05)$ produzidas pela ativação do quimiorreflexo periférico com a injeção i.v de cianeto de sódio (40 $\mu \mathrm{g} / 0,1 \mathrm{ml})$ (Fig. 7B).

A figura 5B ilustra também as injeções de moxonidina (5 nmol/50 nl) localizadas fora do NTScom. As injeções que não atingiram o NTScom normalmente atingiram o núcleo motor do hipoglosso (9 de 11 injeções) ou o núcleo grácil (2 de 11 injeções). Essas injeções não promoveram alterações na $\operatorname{PAM}[F(1,33)=0.65$, $\mathrm{p}>0.05]$ e $F C[F(1,33)=0.67, p>0.05]$ basal. 
Figura 5 - Injeção de moxonidina no NTScom em ratos não anestesiados.
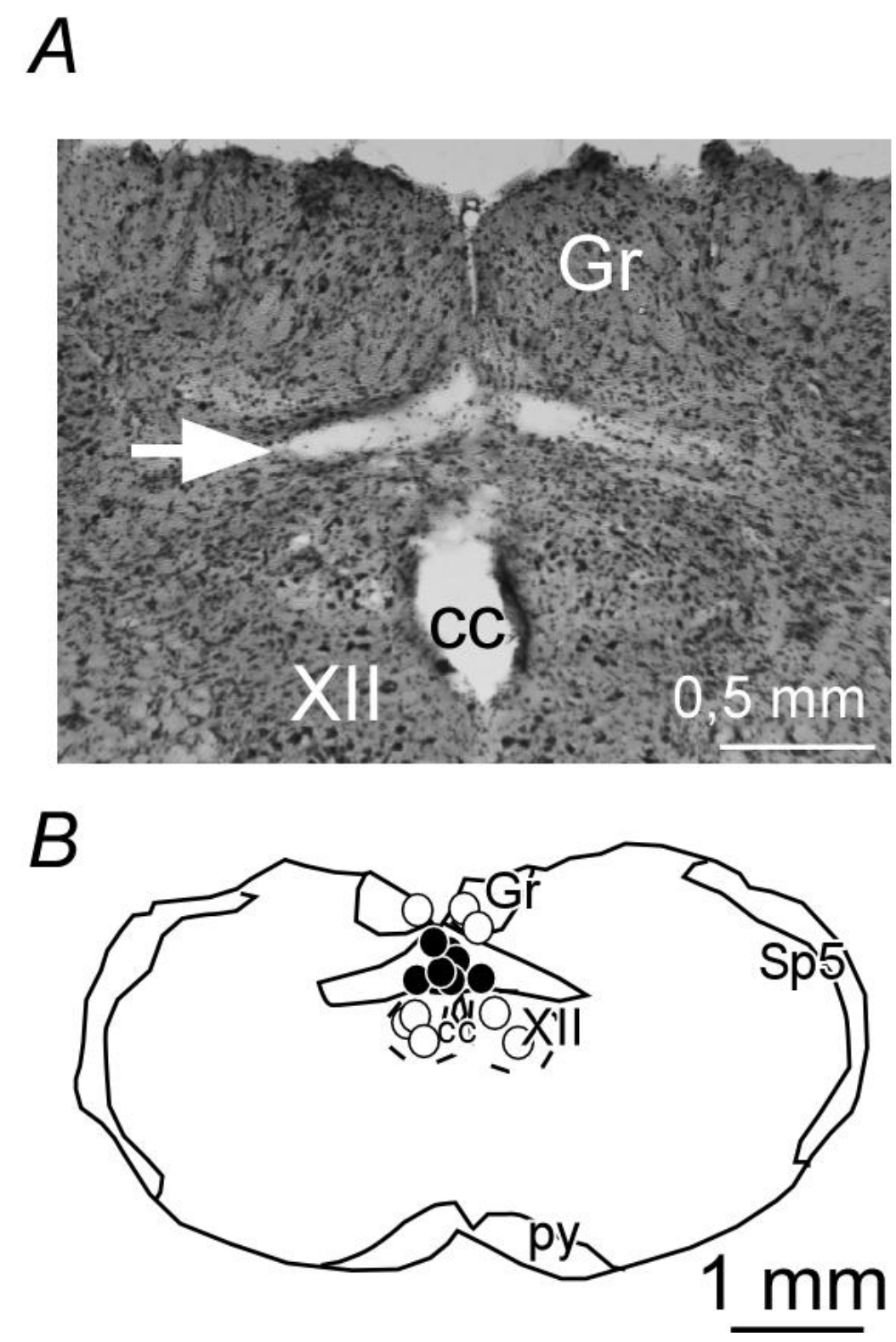

A) Fotomicrografia mostrando o local típico da injeção no NTScom em ratos não anestesiados (seta). Escala $=1 \mathrm{~mm}$. B) Desenho esquemático mostrando a localização das injeções de moxonidina no NTScom (círculos pretos). Círculos brancos ilustram as injeções de moxonidina na região do núcleo Grácil e na região do núcleo motor do hipoglosso (secção coronal: 14,3 mm caudal ao Bregma, ver Paxinos e Watson, 1998). Escala $=1 \mathrm{~mm}$. Abreviaturas: cc, canal central; Gr, núcleo grácil; py, trato piramidal; Sp5, trato espinhal do trigêmio; XII, núcleo motor do hipoglosso. 
Figura 6 - Efeitos cardiovasculares promovidos pela injeção de moxonidina no NTScom em ratos não anestesiados.

$A$

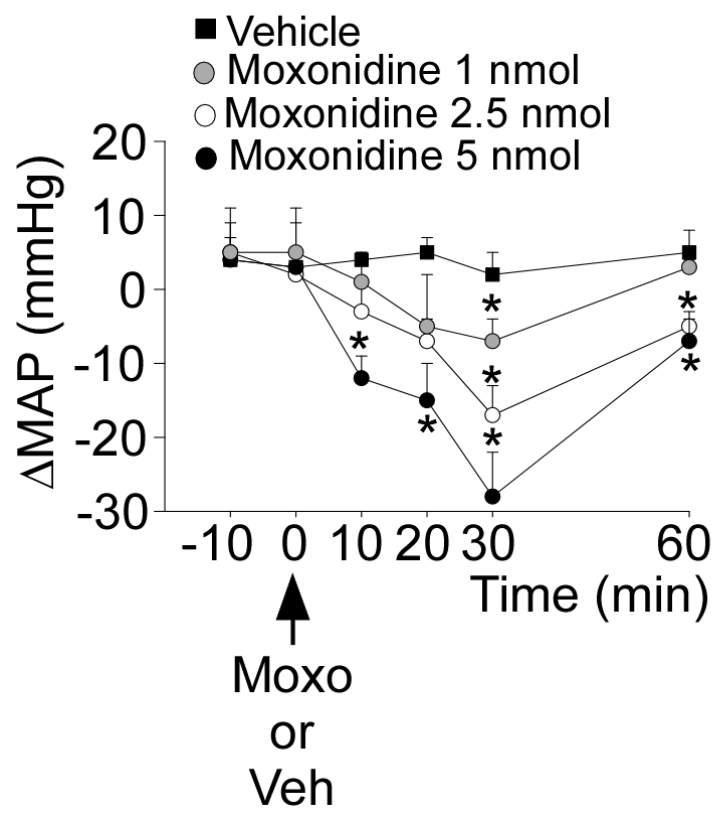

$B$

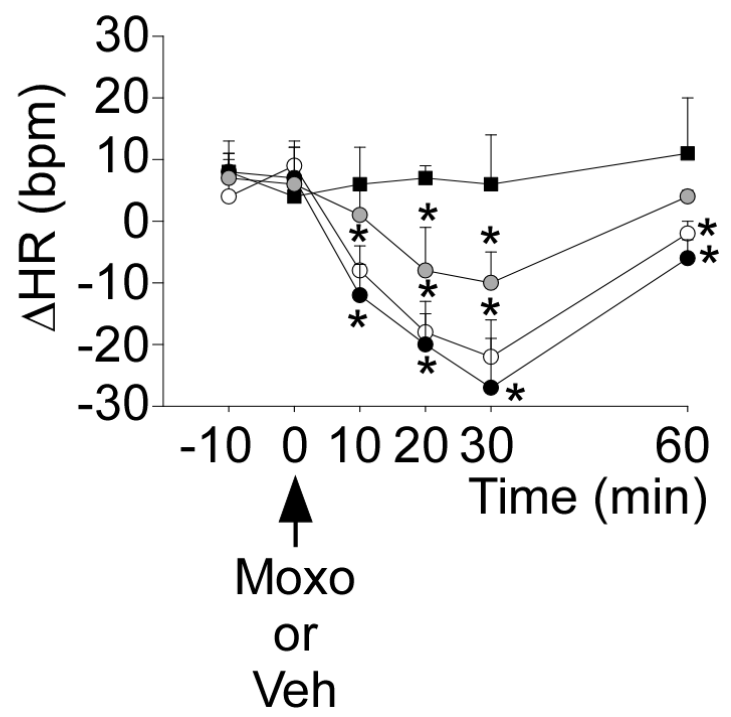

A e B) Alterações na pressão arterial média ( $\triangle$ MAP) e frequência cardíaca $(\Delta H R)$, respectivamente, produzidas pela injeção de veículo ou moxonidina $(1,2,5$, e $5 \mathrm{nmol} / 50 \mathrm{nl})$ no NTScom em ratos não anestesiados. Os resultados estão apresentados como média \pm EPM. *Diferente de veículo $(p<0,05)$. Análise de variância de duas vias, seguido do teste de Student-Newman-Keuls, $n=7 / g$ rupo. 
Figura 7 - Efeitos da injeção de moxonidina no NTScom nas respostas cardiovasculares promovidas pela ativação e desativação do barorreflexo e ativação do quimiorreflexo periférico.

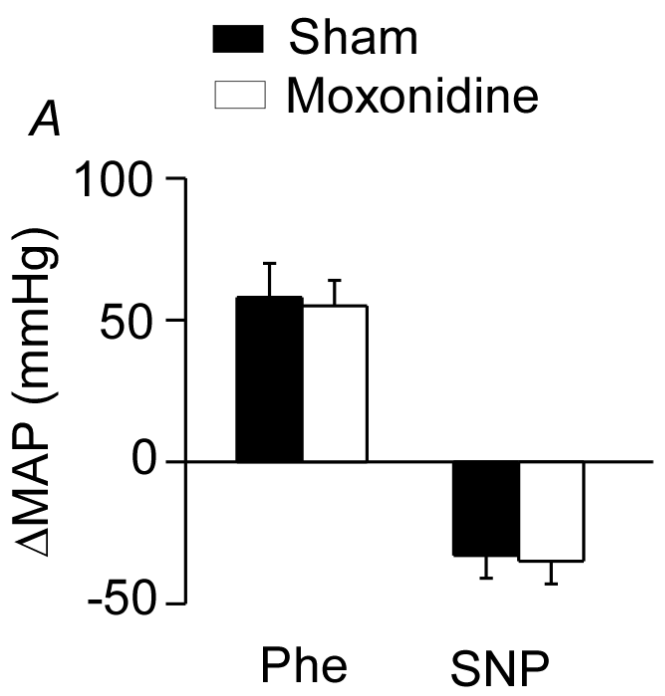

$B$
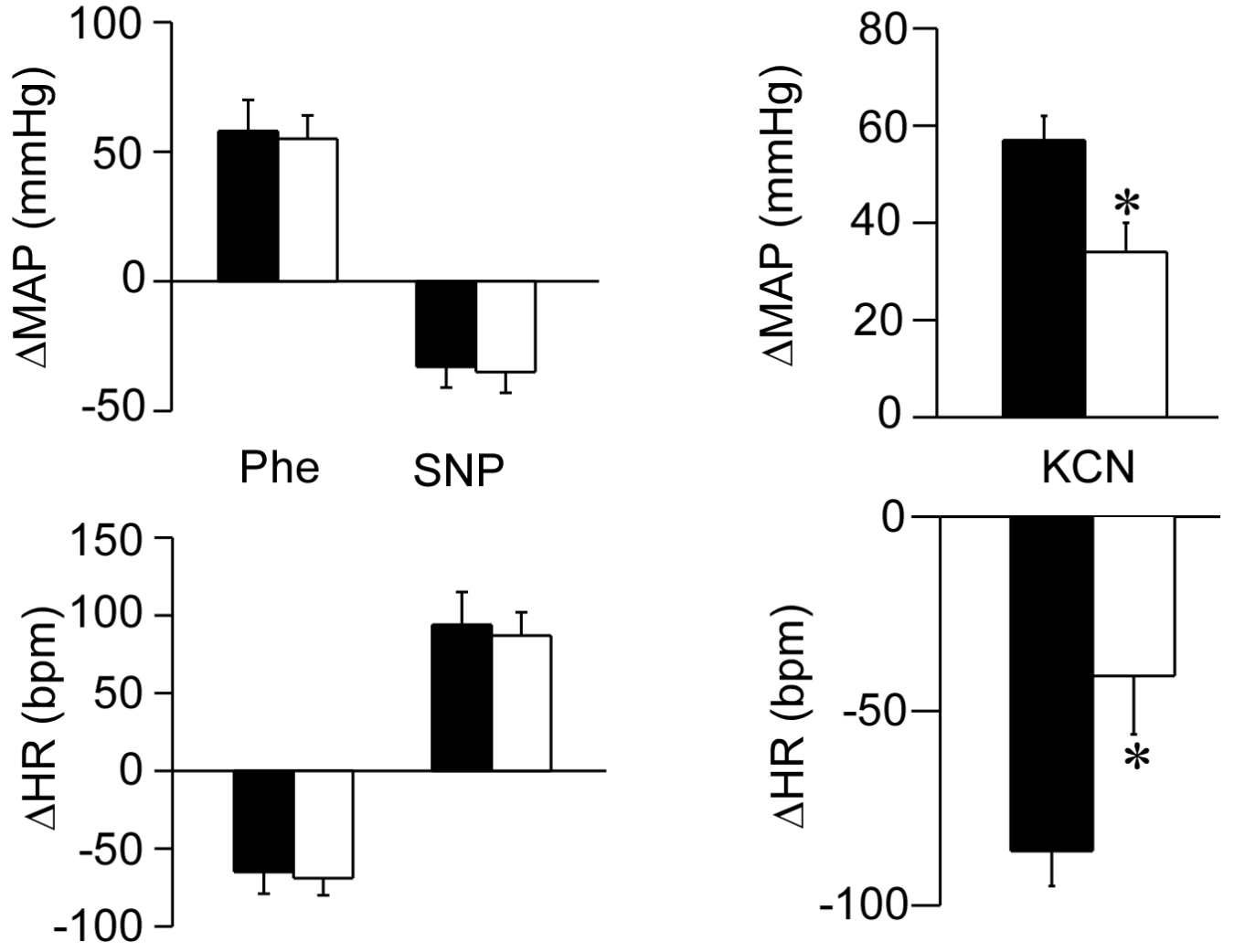

A-B) Alterações na PAM ( $\triangle$ MAP) e FC ( $\triangle \mathrm{HR}$ ) produzidas pela injeção intravenosa (i.v) de fenilefrina (Phe - $5 \mu \mathrm{g} / \mathrm{kg}$ ), nitroprussiato de sódio (SNP - $30 \mu \mathrm{g} / \mathrm{kg}$ ) e cianeto de sódio (KCN - $40 \mu \mathrm{g} / 0,1 \mathrm{ml}$ ) em animais que receberam a injeção de veículo ou moxonidina no NTScom. *Diferente de veículo $(p<0,05)$. Análise de variância de uma via, seguido do teste de Student-Newman-Keuls, $n=7 / g r u p o$. 


\subsection{Respostas cardiovasculares e simpáticas produzidas pela injeção de moxonidina no NTScom em ratos anestesiados}

Os resultados apresentados até o presente momento mostraram que a moxonidina pode atuar na região do NTScom para produzir hipotensão e bradicardia. Dessa maneira, surgiu a hipótese de que a região comissural do NTS poderia estar envolvida nos efeitos anti-hipertensivos promovidos pela moxonidina. Os experimentos propostos a seguir visaram analisar os efeitos na pressão arterial, frequência cardíaca e na atividade simpática eferente promovidos pela injeção de moxonidina no NTScom em ratos normotensos e anestesiados. Utilizamos o modelo experimental em animais anestesiados para podermos avaliar se os efeitos antihipertensivos da moxonidina iriam também promover alterações na atividade simpática eferente.

Da mesma maneira que foi apresentado em animais não anestesiados, as injeções localizadas no NTScom estavam localizadas $400 \mu \mathrm{m}$ caudal ao calamus scriptorius (Figs. 8A e 8B). A figura 8A mostra uma fotomicrografia de uma injeção típica localizada no NTScom. Ao analisarmos o espalhamento das esferas de látex, que estavam junto com a droga, observamos que a injeção espalhou-se cerca de $500 \mu \mathrm{m}$ bilateralmente ao centro da injeção e aproximadamente $300 \mu \mathrm{m}$ no sentido rostro-caudal a partir do centro de injeção (Fig. 8A).

$\mathrm{Em}$ ratos anestesiados com uretana (parâmetros cardiovasculares basais PAM: $117 \pm 4 \mathrm{mmHg}$ e FC: $381 \pm 19 \mathrm{bpm}, \mathrm{n}=6 / \mathrm{grupo}$ ), moxonidina ( 2,5 e $5 \mathrm{nmol} / 50$ nl) injetado no NTScom reduziu PAM $(\Delta=-12 \pm 3$ e $-24 \pm 4$, vs. veículo: $\Delta=3 \pm 3$ $\mathrm{mmHg})[\mathrm{F}(3,37)=27.04, \mathrm{p}<0.05], \mathrm{FC}(\Delta=-18 \pm 5$ e $-25 \pm 9$, vs. veículo: $\Delta=+3 \pm$ $4 \mathrm{bpm})[\mathrm{F}(3,37)=114.18, \mathrm{p}<0.05]$ e atividade simpática eferente (AS) $(\Delta=-11 \pm 2 \mathrm{e}$ $-25 \pm 3 \%)[F(3,37)=34.17, p<0.05]$ (Figs. 9A-D). Os efeitos hipotensores, bradicárdicos e de simpatoinibição produzidos pela moxonidina tiveram uma resposta lenta e foram necessários 10 minutos para iniciar uma redução da PAM, FC e AS, atingindo o pico da resposta aos 30 minutos quando comparado ao grupo controle (Figs. 9B-D). A dose mais baixa de moxonidina ( $1 \mathrm{nmol} / 50 \mathrm{nl})$ injetada no NTScom não produziu alterações na $\operatorname{PAM}(\Delta=+2 \pm 3 \mathrm{mmHg}$, vs. veículo: $\Delta=+3 \pm 3$ $\mathrm{mmHg}, \mathrm{p}>0.05)$, FC ( $\Delta=-8 \pm 3$, vs. veículo: $\Delta=+3 \pm 4 \mathrm{bpm}, \mathrm{p}>0.05)$ e AS $(\Delta=-3 \pm$ $5 \%, p>0.05)$ (Figs. 9B-D). 
A figura 8B ilustra também as injeções de moxonidina $(5 \mathrm{nmol} / 50 \mathrm{nl})$ localizadas fora do NTScom. As injeções que não atingiram o NTScom normalmente atingiram o núcleo motor do hipoglosso (9 de 15 injeções) ou o núcleo grácil (6 de 15 injeções). Essas injeções não promoveram alterações na $\operatorname{PAM}[F(1,26)=0.57$, $p>0.05]$, $F C[F(1,26)=0.27, p>0.05]$ ou AS $[F(1,26)=0.84, p>0.05]$ basal. 
Figura 8 - Localização da injeção de moxonidina no NTScom em ratos anestesiados e normotensos.

$A$

$B$
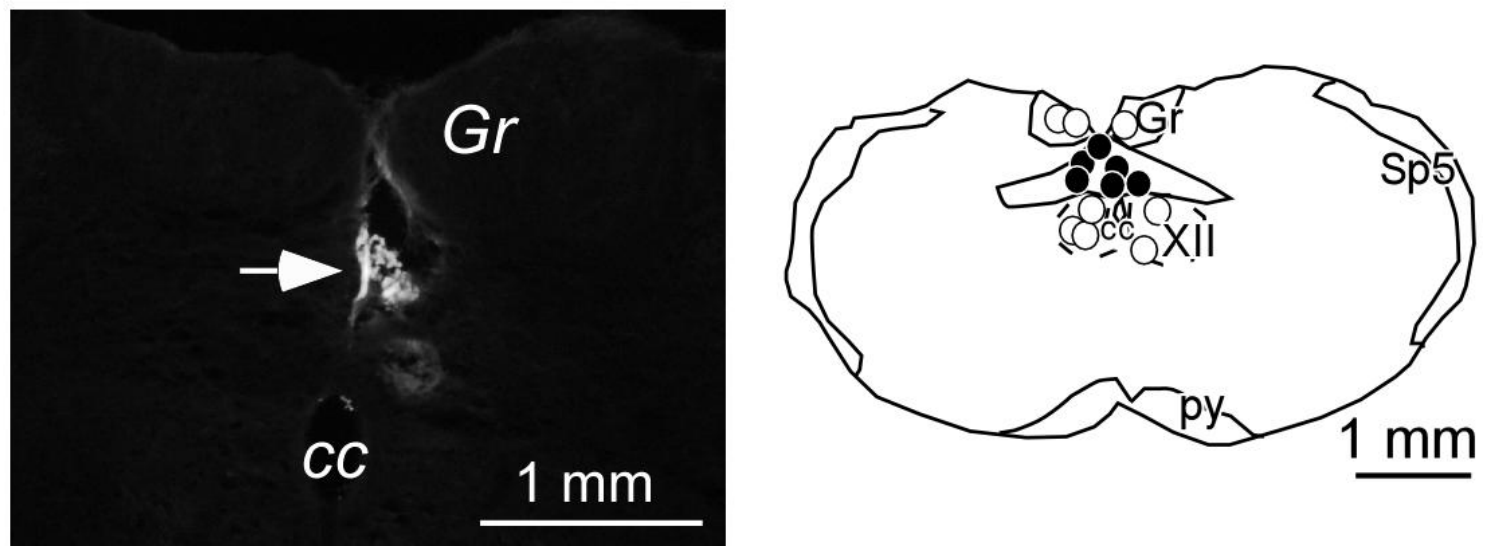

A) Fotomicrografia mostrando o local típico da injeção de moxonidina na região do NTScom (seta). Escala = $1 \mathrm{~mm}$. B) Diagrama mostrando o local das injeções de moxonidina revelado pela presença de microesferas fluorescentes de látex incluídos juntamente com a moxonidina (círculos pretos). Círculos brancos ilustram as injeções de moxonidina na região do núcleo Grácil e na região do núcleo motor do hipoglosso (secção coronal: 14,3 mm caudal ao Bregma, ver Paxinos e Watson, 1998). Escala $=1 \mathrm{~mm}$. Abreviações: cc, canal central; Gr, núcleo grácil; py, trato piramidal; Sp5, núcleo espinal do trigêmio; XII, núcleo motor do hipoglosso. 
Figura 9 - Respostas cardiovasculares e simpáticas produzidas pela injeção de moxonidina no NTScom em ratos anestesiados.

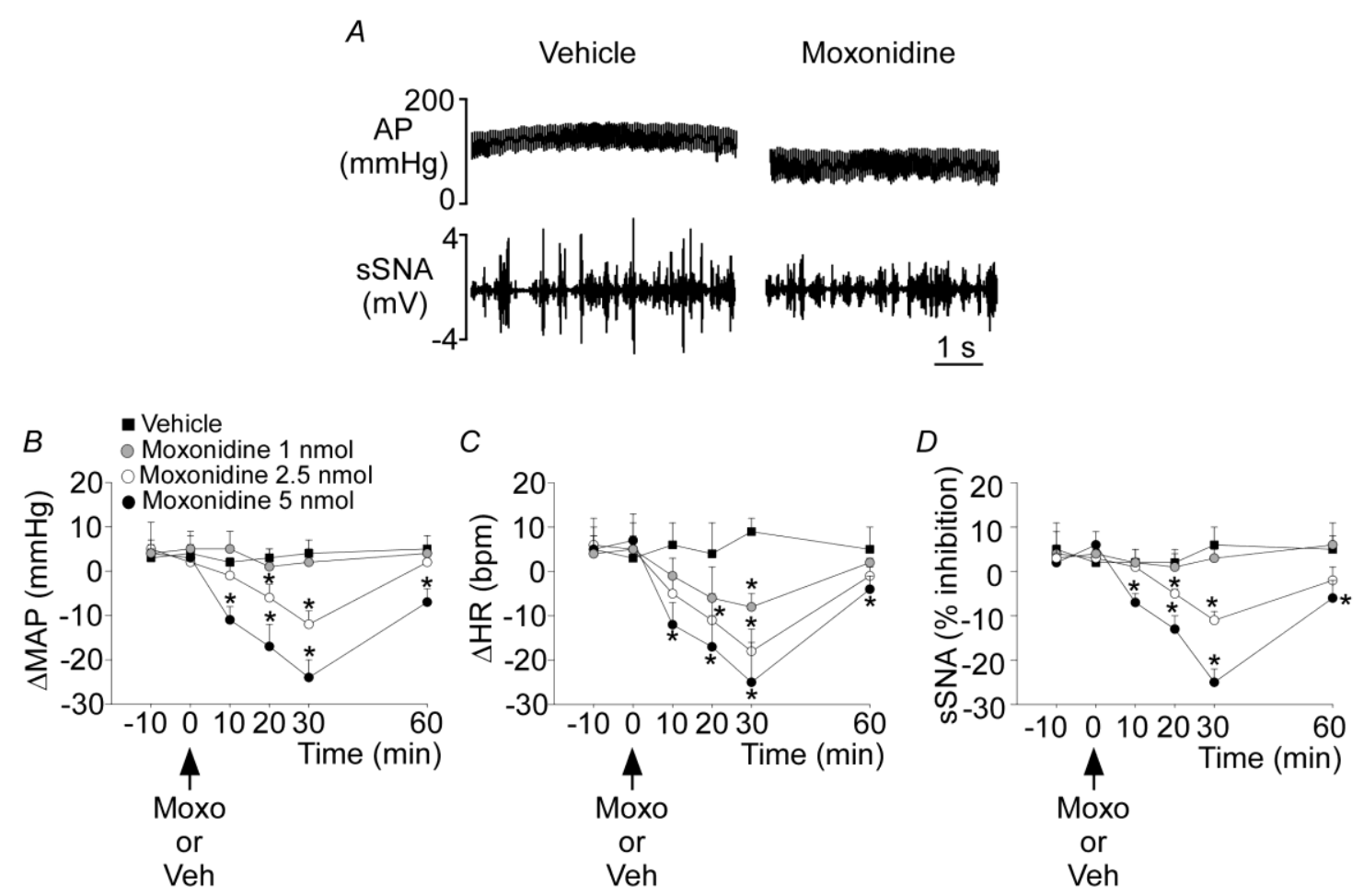

A) Traçado representativo mostrando os efeitos na pressão arterial (AP) e na atividade simpática eferente do nervo esplâncnico (sSNA) produzidas pela injeção de veículo (controle: $50 \mathrm{nl}$ ) ou moxonidina $(5 \mathrm{nmol} / 50 \mathrm{nl})$ na região do NTScom. As respostas foram registradas 30 min após a injeção de veículo ou moxonidina. B, C e D) alterações na pressão arterial média ( $\triangle \mathrm{MAP})$, frequência cardíaca $(\Delta \mathrm{HR})$ e atividade eferente do nervo simpático esplâncnico (sSNA), produzidos pela injeção de veículo (50 nl) ou moxonidina (1, 2,5 e $5 \mathrm{nmol} / 50 \mathrm{nl}$ ) no NTScom de ratos anestesiados. Os resultados estão expressos como médias \pm erro padrão da média. *Diferente de veículo $(p<0,05)$. Análise de variância de duas vias, seguido do teste de Student-Newman-Keuls; $n=6 / g$ rupo de ratos. 


\subsection{Respostas cardiovasculares e simpáticas promovidas pela injeção de moxonidina no NTScom após o bloqueio seletivo de receptores adrenérgicos $\alpha_{2}$}

Os mecanismos neurais na qual a moxonidina produz os seus efeitos antihipertensivos ainda é motivo de várias controvérsias na literatura. A discussão mais proeminente é tentar esclarecer em qual tipo de receptor (receptores adrenérgicos $\alpha_{2}$ ou imidazólicos) a moxonidina estaria atuando para produzir os seus efeitos farmacológicos. Baseando-se nessas controvérsias, o próximo conjunto de experimentos foi elaborado para tentar esclarecer se a moxonidina poderia estar atuando em receptores adrenérgicos $\alpha_{2}$ centrais para exercer seus efeitos hipotensores e simpatoinibitórios.

A injeção do antagonista de receptores adrenérgicos $\alpha_{2}$ ioimbina (10 nmol/50 nl) no NTScom foi capaz de bloquear as respostas hipotensora ( $\Delta=-3 \pm 2 \mathrm{mmHg}$, vs. moxonidina: $\Delta=-22 \pm 4 \mathrm{mmHg})[F(3,49)=78,46 ; p<0,01]$ e de simpatoinibição $(\Delta$ $=-2 \pm 5 \%$, vs. moxonidina: $\Delta=-18 \pm 3 \%)[F(3,49)=24,13 ; p<0,05]$ produzida pela injeção de moxonidina (5 nmol/50 nl) no NTScom (Figs. 10A, 10 B e 10D). A injeção prévia de ioimbina no NTScom não alterou a bradicardia $(\Delta=-23 \pm 7$ bpm, vs. moxonidina: $\Delta=-19 \pm 6 \mathrm{bpm})[\mathrm{F}(3,49)=0,65 ; \mathrm{p}>0,05]$ produzida pela injeção de moxonidina (Fig. 10C)

Apenas a injeção de ioimbina no NTScom não foi capaz de promover alterações na PAM ( $\Delta=6 \pm 5$, vs. veículo: $\Delta=3 \pm 2 \mathrm{mmHg}, \mathrm{p}>0,05)$ e a atividade simpática eferente ( $\Delta=7 \pm 4$, vs. veículo: $\Delta=3 \pm 3 \%$, p>0,05) (Fig. 10B e 10D).

Da mesma maneira, a injeção do antagonista de receptores adrenérgicos $\alpha_{2}$ RX821002 (10 nmol/50 nl) no NTScom foi capaz de bloquear as respostas hipotensora ( $\Delta=-5 \pm 7 \mathrm{mmHg}$, vs. moxonidina: $\Delta=-25 \pm 6 \mathrm{mmHg})[\mathrm{F}(3,57)=$ $118,32 ; \mathrm{p}<0,01]$ e de simpatoinibição ( $\Delta=-3 \pm 4 \%$, vs. moxonidina: $\Delta=-19 \pm 4 \%$ ) $[F(3,57)=87,22 ; p<0,05]$ produzida pela injeção de moxonidina $(5 \mathrm{nmol} / 50 \mathrm{nl}) \mathrm{no}$ NTScom (Figs. 11A e 11C). A injeção prévia de RX821002 no NTScom não alterou a bradicardia $(\Delta=-17 \pm 5$ bpm, vs. moxonidina: $\Delta=-21 \pm \mathrm{bpm})[\mathrm{F}(3,57)=0,76$; p>0,05] produzida pela injeção de moxonidina (Fig. 11B)

Apenas a injeção de RX821002 no NTScom não foi capaz de promover alterações na PAM ( $\Delta=3 \pm 3$, vs. veículo: $\Delta=1 \pm 2 \mathrm{mmHg}, \mathrm{p}>0,05)$ e a atividade simpática eferente ( $\Delta=4 \pm 2$, vs. veículo: $\Delta=2 \pm 2 \%, \mathrm{p}>0,05)$ (Fig. 11A e 11-C). 
Figura 10 - Respostas cardiovasculares e simpáticas produzidas pela injeção de moxonidina no NTScom em ratos que receberam a injeção prévia de ioimbina.
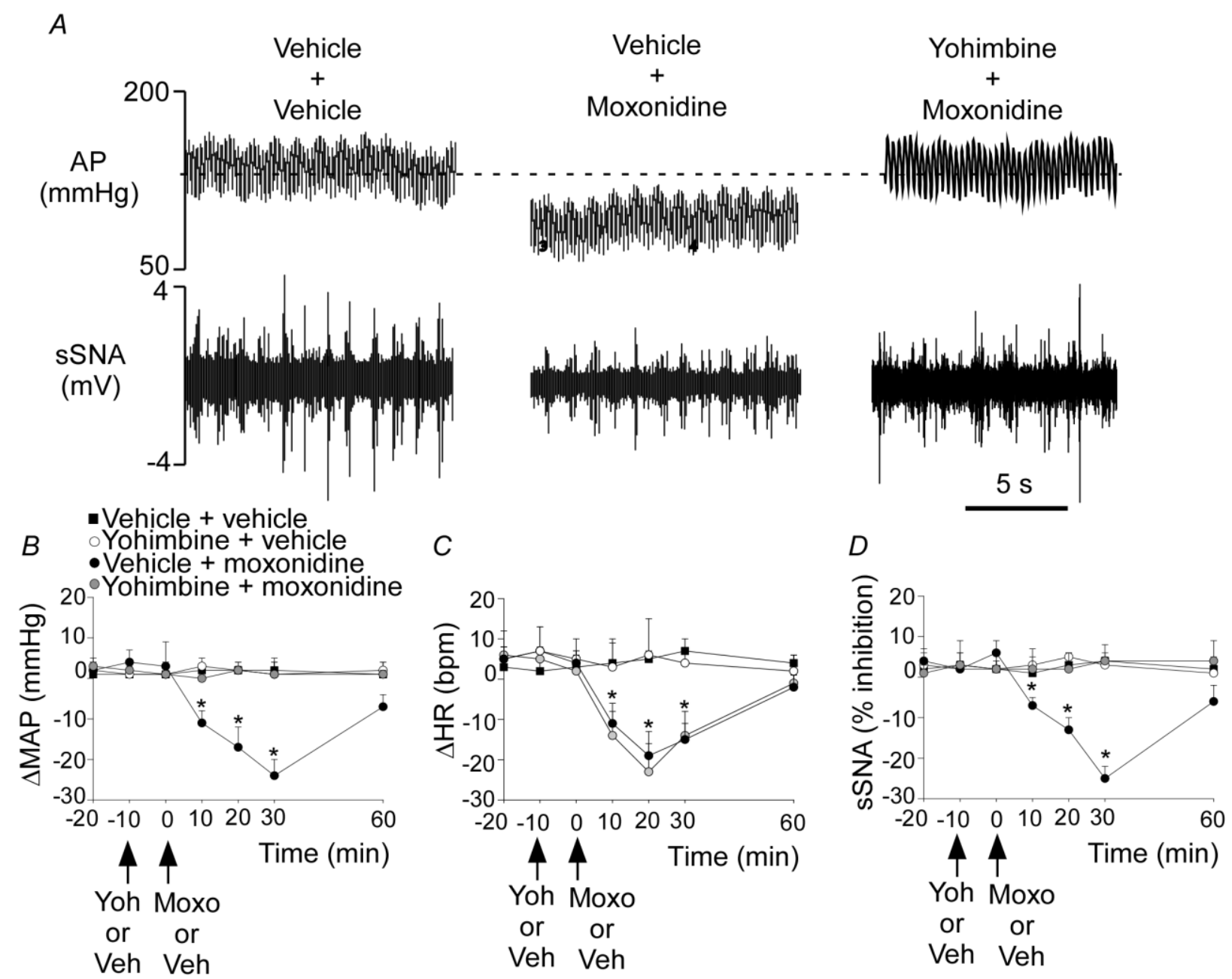

A) Traçado representativo mostrando os efeitos na pressão arterial (AP) e na atividade simpática eferente do nervo esplâncnico (sSNA) produzidas pela injeção de veículo + ioimina $(10 \mathrm{nmol} / 50 \mathrm{nl})$ e veículo + moxonidina $(5 \mathrm{nmol} / 50 \mathrm{nl})$ na região do NTScom. $B, C$ e D) alterações na pressão arterial média $(\triangle \mathrm{MAP})$, frequência cardíaca $(\Delta \mathrm{HR})$ e atividade eferente do nervo simpático esplâncnico (sSNA), produzidos pela injeção de veículo ou ioimbina $(10 \mathrm{nmol} / 50 \mathrm{nl})$ e veículo ou moxonidina $(5 \mathrm{nmol} / 50 \mathrm{nl})$ no NTScom de ratos anestesiados. Os resultados estão expressos como médias \pm erro padrão da média. ${ }^{*}$ Diferente de veículo $(p<0,05)$. Análise de variância de duas vias, seguido do teste de Student-Newman-Keuls; $n=6 / g$ rupo de ratos. 
Figura 11- Respostas cardiovasculares e simpáticas produzidas pela injeção de moxonidina no NTScom em ratos que receberam a injeção prévia de $R \times 821002$.
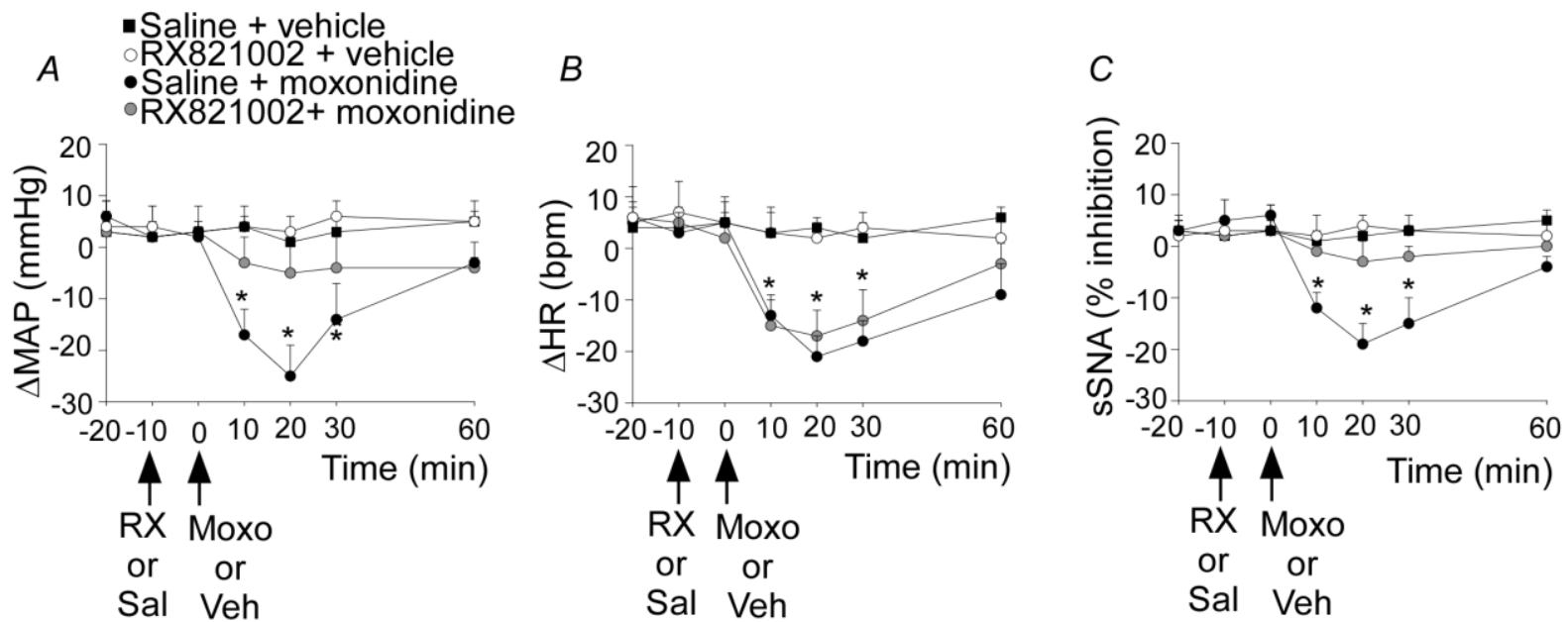

A, B e C) alterações na pressão arterial média (MAP), frequência cardíaca (HR) e atividade eferente do nervo simpático esplâncnico (sSNA), produzidos pela injeção de veículo ou RX821002 (10 nmol/50 nl) e veículo ou moxonidina $(5 \mathrm{nmol} / 50 \mathrm{nl}) \mathrm{no}$ NTScom de ratos anestesiados. Os resultados estão expressos como médias \pm erro padrão da média. *Diferente de veículo $(p<0,05)$; Análise de variância de duas vias, seguido do teste de Student-Newman-Keuls.; $n=5 /$ grupo de ratos. 


\subsection{Respostas cardiovasculares e simpáticas produzidas pela injeção de moxonidina no RVL/C1 em ratos anestesiados}

Parece existir um consenso que o principal local de ação da moxonidina é a região do RVL/C1 (PUNNEN et al., 1987), mas ainda existem várias discordâncias na literatura a respeito do local específico de ação da moxonidina. Dessa maneira, o próximo protocolo experimental foi tentar comparar as respostas cardiovasculares e simpáticas promovidas pela injeção de moxonidina na região RVL/C1 com a injeção no NTScom.

As figuras $12 \mathrm{~A}$ e $12 \mathrm{~B}$ mostram o local típico das injeções de moxonidina na região do $\mathrm{RVL/C1}$. As injeções foram localizadas ventralmente ao núcleo ambíguo e aproximadamente 200 - $400 \mu \mathrm{m}$ caudal a porção caudal do núcleo motor do nervo facial. Essa região esta descrita como sendo uma região pressora, na qual a injeção de L-glutamato promove clássicas respostas pressoras em ratos (DE PAULA; MACHADO, 2000). Baseado na área de distribuíção do corante (esferas de látex), observamos um espalhamento de $300 \mu \mathrm{m}$, no sentido rostro-caudal, a partir do centro da injeção (dados não mostrados).

Em ratos anestesiados com uretana (parâmetros cardiovasculares basais PAM: $115 \pm 6$ mmHg e FC: $374 \pm 21$ bpm, $n=5-6 /$ grupo), moxonidina (1; 2,5 e 5 $\mathrm{nmol} / 50 \mathrm{nl})$ injetado bilateralmente na região $\mathrm{RVL} / \mathrm{C} 1$ reduziu PAM $(\Delta=-15 \pm 5,-27$ \pm 4 e $-37 \pm 5$, vs. veículo: $\Delta=+6 \pm 4 \mathrm{mmHg})[\mathrm{F}(3,74)=139.75, \mathrm{p}<0.01]$ e AS $(\Delta=-$ $18 \pm 6,-42 \pm 4$ e $-61 \pm 7 \%)[F(3,74)=218.36, p<0.01]$ (Figs. 13A-C). Apenas a maior dose de moxonidina $(5 \mathrm{nmol} / 50 \mathrm{nl})$ promoveu redução significativa da $\mathrm{FC}(\Delta=$ $-7 \pm 2$, vs. veículo: $\Delta=+8 \pm 5$ bpm, $\mathrm{p}<0.05$ ) (Fig. 13B).

Independente das doses de moxonidina utilizadas no presente estudo, as injeções de moxonidina na região do RVL/C1 sempre produziram maiores hipotensões e redução da atividade simpática quando comparado as injeções no NTScom (Figs. 9 e 13), [F(5, 38) = 44.51, p<0.01].

A figura 12 ilustra também as injeções de moxonidina (5 nmol/50 nl) localizadas fora do RVL/C1. Realizamos injeções de moxonidina na região da Rafa Palidus $(n=4)$, região essa medial ao RVL/C1. Essas injeções não promoveram alterações na PAM $[F(1,42)=1,03, p>0.05]$, $F C[F(1,42)=0,39 p>0.05]$ ou AS $[F(1$, 42) $=1,12, p>0.05]$ basal. 
Figura 12 - Localização da injeção de moxonidina na região RVL/C1 em ratos anestesiados.
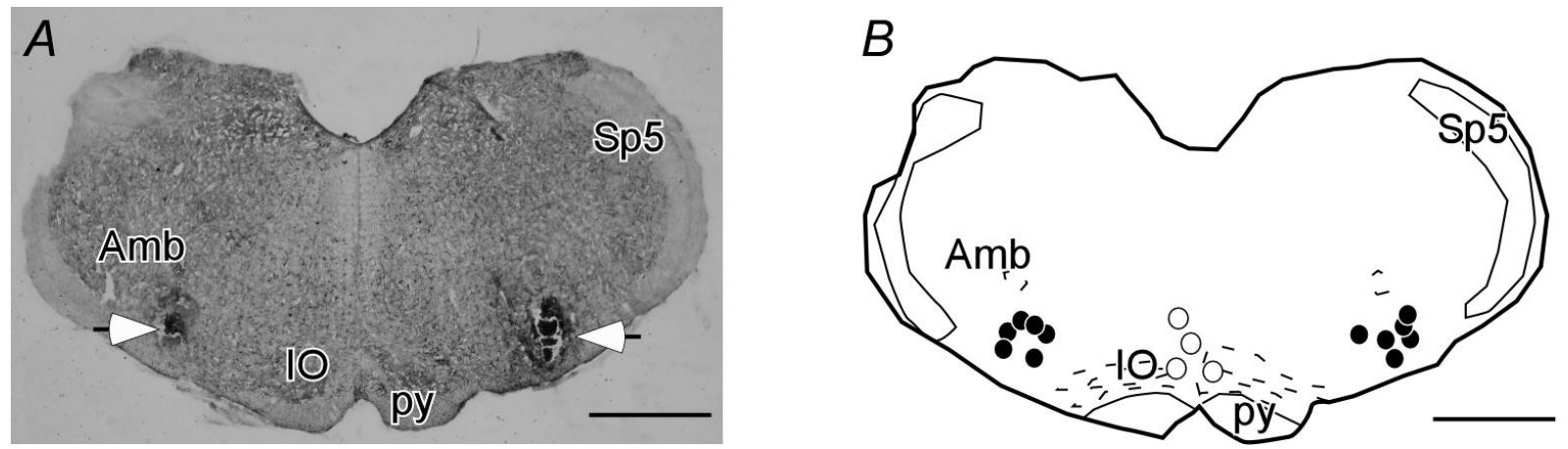

A) Fotomicrografia mostrando o local típico da injeção bilateral de moxonidina na região do $\mathrm{RVL} / \mathrm{C} 1$ (seta). Escala $=1 \mathrm{~mm}$. B) Diagrama mostrando o local das injeções bilaterais de moxonidina revelado pela presença de microesferas fluorescentes de látex incluídos juntamente com a moxonidina (círculos pretos). Círculos brancos ilustram as injeções de moxonidina na região do núcleo da Rafe Palidus (secção coronal: $12,3 \mathrm{~mm}$ caudal ao bregma, ver Paxinos e Watson, 1998). Escala = $1 \mathrm{~mm}$. Abreviações: Amb, núcleo ambíguo; IO, oliva inferior; py, trato piramidal; Sp5, núcleo espinal do trigêmio. 
Figura 13 - Respostas cardiovasculares e simpáticas produzidas pela injeção de moxonidina na região $R V L / C 1$ em ratos anestesiados.
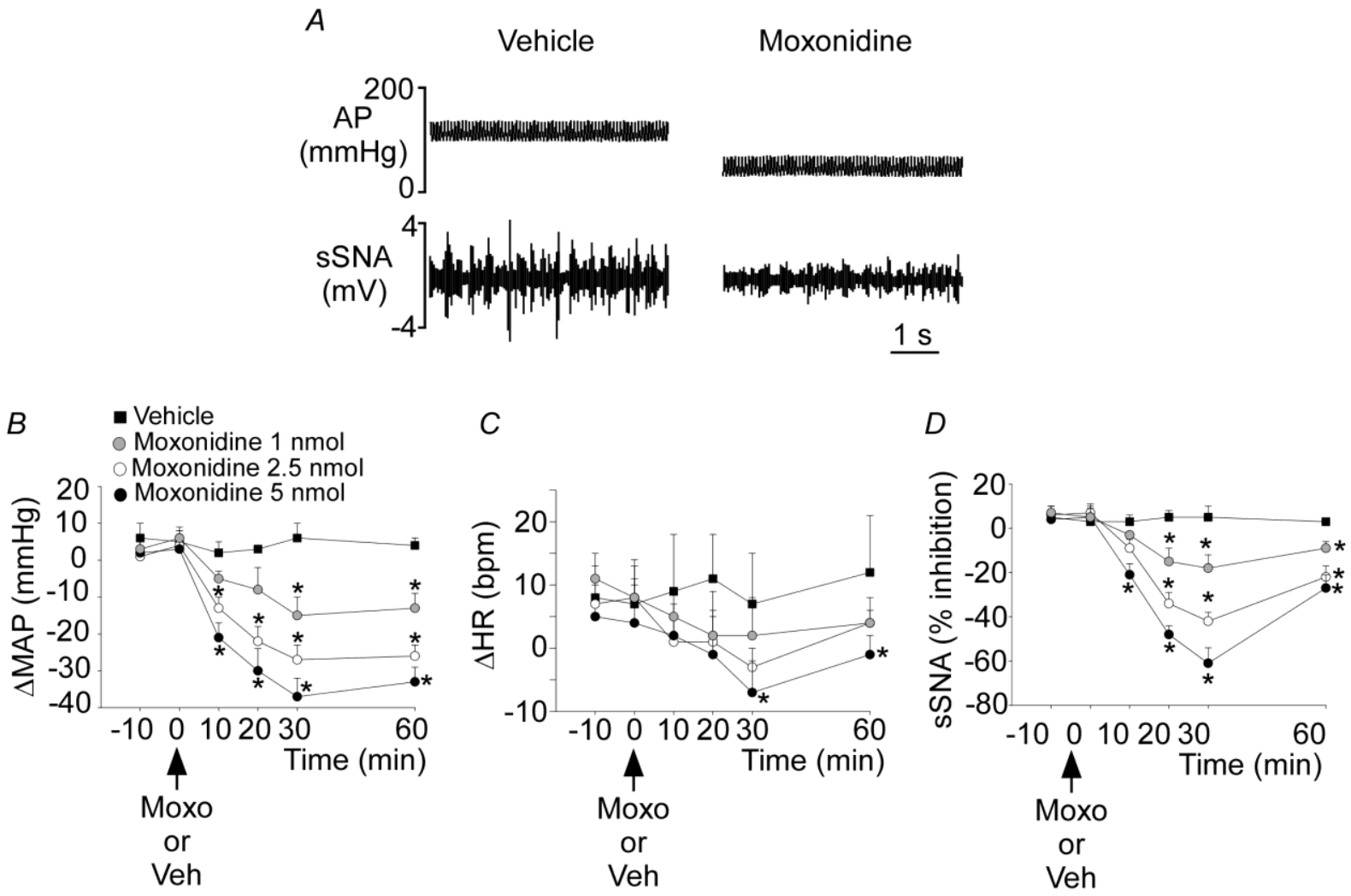

A) Traçado representativo mostrando os efeitos na pressão arterial (AP) e na atividade simpática eferente do nervo esplâncnico (sSNA) produzidas pela injeção de veículo (controle: $50 \mathrm{nl}$ ) ou moxonidina $(5 \mathrm{nmol} / 50 \mathrm{nl}$ ) na região do $\mathrm{RVL} / \mathrm{C} 1$. As respostas foram registradas 30 min após a injeção de veículo ou moxonidina. $B, C$ e D) alterações na pressão arterial média $(\triangle \mathrm{MAP})$, frequência cardíaca $(\Delta \mathrm{HR})$ e atividade eferente do nervo simpático esplâncnico (sSNA), produzidos pelar injeção de veículo (50 nl) ou moxonidina (1, 2,5 e $5 \mathrm{nmol} / 50 \mathrm{nl}$ ) no $\mathrm{RVL} / \mathrm{C} 1$ de ratos anestesiados. Os resultados estão expressos como médias \pm erro padrão da média. *Diferente de veículo $(p<0,05)$. Análise de variância de duas vias, seguido do teste de Student-Newman-Keuls; $n=6 / g$ rupo de ratos. 


\subsection{Efeitos da injeção de moxonidina no NTScom sobre a atividade elétrica dos neurônios pré-simpáticos do RVL/C1}

Sabe-se que a atividade simpática eferente é principalmente controlada pelos neurônios pré-motores simpáticos localizados no bulbo ventrolateral (GUYENET, 2006). Dessa maneira, o próximo protocolo experimental foi elaborado para tentar analisar o quanto as respostas simpatoinibitórias, promovidas pela injeção de moxonidina no NTScom, dependem de uma inibição dos neurônios pré-simpáticos da região $\mathrm{RVL/C1}$.

A identificação dos neurônios pré-motores simpáticos da região RVL/C1 foram baseados nos seguintes critérios: a) localização, b) atividade espontânea e c) projeção para a coluna intermédio-lateral da medula espinal torácica (latência em média de $3.6 \pm 0.4$ ms) (Fig. 14B). A localização dos neurônios, bem como o fenótipo dos neurônios (adrenérgicos ou não adrenérgicos) foi determinada utilizando a técnica de marcação justacelular (PINAULT, 1996). Essa técnica consiste na passagem de corrente elétrica (3.4 $\pm 0.2 \mathrm{nA}$ por aproximadamente 2 minutos) através da pipeta de registro (Fig. 14C). Foram registrados 15 neurônios com as características descritas acima ( $\mathrm{n}=2-3$ neurônios/rato; $\mathrm{N}=6$ ratos). A figura 14A ilustra a redução da atividade de um neurônio pré-motor simpático do RVL após a injeção de moxonidina (5 nmol/50nl) no NTScom. Em média, a injeção de moxonidina no NTScom promoveu uma redução da atividade dos neurônios prémotores simpáticos do RVL $(15 \pm 1.8 \mathrm{~Hz}$, vs. veículo: $21.3 \pm 1.2 \mathrm{~Hz} ; 28 \%$ de redução; $p<0.05$; Fig. 14A e 14D). A redução da atividade neuronal é compatível com a redução da pressão arterial $(22 \pm 5 \mathrm{mmHg})$ promovida pela injeção de moxonidina no NTScom. Todos os neurônios pré-motores simpáticos do RVL analisados foram inibidos pela injeção de moxonidina no NTScom (variação de 10 a 47\% de inibição).

As localizações dos 15 neurônios registrados e marcados com biotinamida estão ilustrados nas figuras 14E e 14F. Dez neurônios foram imunorreativos para tirosina hidroxilase (TH) e cinco neurônios não foram imunorreativos para TH (Figs. $14 \mathrm{~F}$ e 14G). Todos os neurônios foram encontrados na região $\mathrm{RVL}$ de maior concentração de neurônios catecolaminérgicos que definem essa região como uma região pressora (ROSS et al., 1984; SCHREIHOFER; GUYENET, 1997). 
Figura 14 - Efeitos da injeção de moxonidina no NTScom sobre a atividade elétrica dos neurônios pré-motores simpáticos do RVL/C1 em ratos anestesiados.
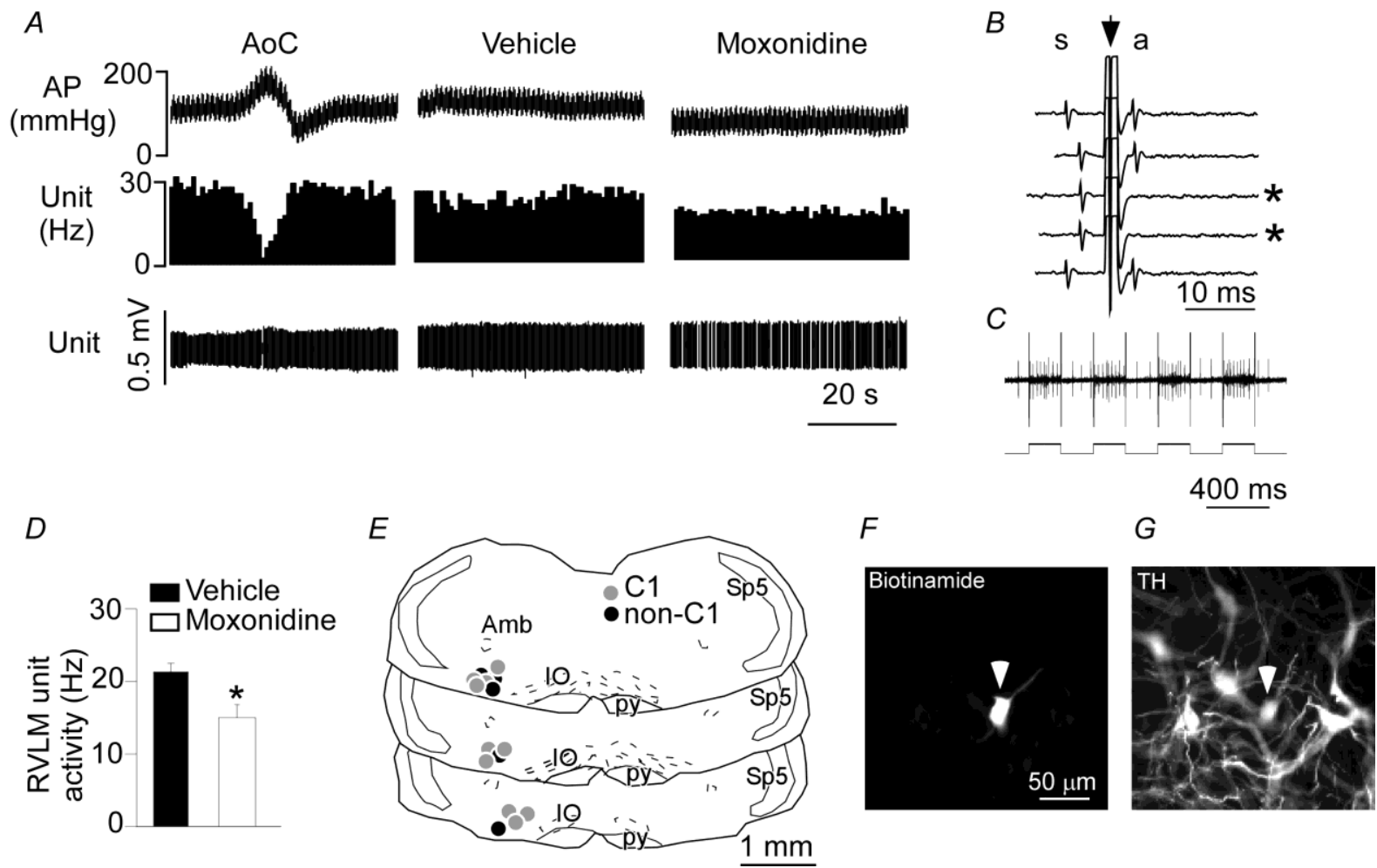

A) Registro da atividade elétrica de um neurônio pré-motor simpático do RVL/C1 que é silenciado após um aumento da pressão arterial por meio de uma oclusão da artéria aorta abdominal (AoC). Efeitos da administração de veículo ou moxonidina (5 nmol/50 nl) no NTScom sobre a atividade elétrica do mesmo neurônio pré-motor simpático do RVL/C1. B) Teste de colisão no neurônio registrado em A, mostrando que esse neurônio projeta-se para a coluna intemédio-lateral na medula espinal torácica (T2-T4) (*indica o momento da colisão entre o potencial elétrico espontâneo (s) do neurônio pré-motor simpático do RVL/C1 com o potencial elétrico gerado (a) pela estimulação elétrica da região T2-T4 da medula espinal). C) procedimento utilizado para realizar a técnica de marcação justacelular com biotinamida (traçado superior: registro unitário do neurônio pré-motor simpático do RVL/C1; traçado inferior: monitoramento da injeção de corrente, 3,4 nA) D) Efeito da injeção de veículo ou moxonidina no NTScom ( $\mathrm{n}=15$ neurônios). E) localização dos neurônios marcados com biotinamida. As três secções coronais representam valores de Bregma (Bregma: -12,3; -12,0 e -11,8 mm baseado no Atlas de encéfalo de rato) (Paxinos e Watson, 1998). F e G são exemplos de um neurônio marcado com biotinamida e imunorreativo para tirosina hidroxilase $(\mathrm{TH})$ (seta). Escala $=50 \mu \mathrm{m}$. Abreviaturas: Amb, núcleo ambiguo; IO, oliva inferior; py, trato piramidal; RPa, rafe palido; Sp5, trato espinal do nervo trigêmeo; VII, núcleo motor facial. Os resultados são apresentados como médias \pm EPM. *Diferente do veículo $(p<0,05)$, teste t não pareado, $n=6 /$ grupo ratos. 


\section{DISCUSSÃO}

O presente estudo é o primeiro a demonstrar os efeitos cardiovasculares e simpáticos produzidos pela injeção de moxonidina (agonista adrenérgico $\alpha_{2} \mathrm{e}$ imidazólico) na região comissural do NTS. Dessa maneira, os resultados do presente estudo sugerem que a moxonidina pode contribuir para a inibição da atividade simpática com consequente redução da pressão arterial, mediante uma inibição da atividade dos neurônios localizados na região comissural do NTS. Ainda não sabemos se essa inibição é de maneira direta ou através da redução da atividade dos neurônios pré-simpáticos da região RVL/C1. Dessa maneira, os presentes resultados procuram incorporar novas informações na literatura de controle neural cardiovascular, sugerindo que os anti-hipertensivos de ação central podem agir em outra região encefálica, diferentemente do que acreditava-se até o presente momento.

Os resultados do presente estudo mostram também que a moxonidina age em receptores adrenérgicos $\alpha_{2}$ na região do NTScom para produzir os seus efeitos cardiovasculares e simpáticos.

\subsection{Envolvimento da região comissural do NTS sobre os efeitos cardiovasculares e simpáticos induzidos pela moxonidina}

Os primeiros indícios de que a moxonidina poderia estar agindo na região do NTS foi o fato de que a lesão eletrolítica da região comissural do NTS foi eficaz em reduzir a hipotensão produzida pela injeção de moxonidina no $4^{\circ} \mathrm{V}$ encefálico. $\mathrm{O}$ mesmo procedimento não foi eficaz em alterar as respostas bradicárdicas produzidas pela moxonidina, sugerindo que os neurônios da região comissural do NTS poderiam ser parte dos mecanismos ativados pela moxonidina, dentro do tronco encefálico, para controlar a pressão arterial, mas não a frequência cardíaca. Dessa maneira, a lesão do NTScom poderia também estar prejudicando sinais importantes que controlam a atividade dos neurônios pré-simpáticos do RVL/C1, uma área importante do circuito bulbar envolvido na regulação cardiovascular. Além disso, mostramos que a injeção de moxonidina diretamente no NTScom promoveu hipotensão, bradicardia e simpatoinibição em ratos não anestesiados e anestesiados, reforçando a hipótese de que fármacos como a moxonidina podem 
atuar em diferentes áreas do tronco encefálico para produzir os seus efeitos antihipertensivos.

Fármacos anti-hipertensivos de ação central, classificados como agonistas adrenérgicos $\alpha_{2}$ e imidazólicos, como a moxonidina, clonidina e rilmenidina, são eficazes no tratamento da hipertensão (EDWARDS et al., 2012; ERNSBERGER et al., 1993). Parece haver um consenso geral de que o principal local de ação desses fármacos seriam os neurônios pré-motores simpáticos da região $\mathrm{RVL} / \mathrm{C} 1$ (GUYENET, 1997; PUNNEN et al., 1987; REIS, 1996). No entanto, o presente estudo fornece evidências de que a moxonidina também poderia atuar em outra importante estrutura bulbar de controle cardiovascular. Essa região seria a região comissural do NTS.

O NTS é considerado o principal núcleo de entrada das aferências autônomas no SNC, em especial no controle cardiorrespiratório, pois essa região recebe as primeiras aferências dos barorreceptores, dos receptores cardiopulmonares e dos quimiorreceptores periféricos (CIRIELLO, 1992; CIRIELLO, 1994; GUYENET, 1990; MACHADO, 2001; SPYER, 1990). Estudos neuroanatômicos mostraram que o NTS é capaz também de integrar diversos mecanismos encefálicos, entre eles circuitos sensoriais e bulbo-pontinos. Dos muitos transmissores e moduladores que são encontrados no NTS, os neurotransmissores adrenérgicos são particularmente importantes, uma vez que estão envolvidos na regulação da pressão arterial (COLOMBARI et al., 2008). A nossa avaliação funcional corrobora com os resultados encontrados em estudos utilizando métodos autorradiográficos, que demonstraram a presença de diferentes subclasses de receptores adrenérgicos no NTS, em especial na região comissural (CARRETTIERO et al., 2012; DUALE et al., 2007). Esses dados reforçam ainda mais os nossos achados funcionais de que a injeção de moxonidina no NTScom promove redução na pressão arterial, da frequência cardíaca e da atividade simpática, sugerindo que a ativação dos receptores adrenérgicos $\alpha_{2}$ poderia reduzir a atividade dos neurônios da região comissural do NTS.

A circuitária bulbar relacionada ao controle cardiovascular envolve o núcleo do trato solitário (NTS), o núcleo ambíguo e a região ventrolateral do bulbo (rostral e caudal) (CIRIELLO, 1994; DAMPNEY, 1994; GUYENET, 1990). Foi proposto que o principal neurotransmissor liberado pelas fibras aferentes do NTS seria o Lglutamato (CIRIELLO, 1994; DAMPNEY, 1994; GORDON, 2002; LEONE, 1989; 
TALMAN, 1980). A partir do NTS, projeções excitatórias são transmitidas para o bulbo ventrolateral caudal ( $C V L)$, o qual recebe aferências provenientes dos barorreceptores arteriais (SCHREIHOFER, 2002; SVED, 2000). Através de mecanismos GABAérgicos, o CVL promove a inibição dos neurônios pré-motores simpáticos do RVL, que modulam a atividade de neurônios pré-ganglionares simpáticos envolvidos no controle da atividade cardíaca e do tônus vasomotor (CIRIELLO, 1994; DAMPNEY, 1994; JESKE, 1993, 1995; MORRISON, 1989, 1991). Paralelamente aos mecanismos de inibição, o RVL também recebe importantes projeções excitatórias (GUYENET, 1987; GRANATA, 2003; HORIUCHI, 2002; ITO; SVED, 1997). Estudos anatômicos e imunoistoquimicos têm demonstrado que o NTS possui conexões monossinápticas com a região do RVL (DAMPNEY, 1994; HANCOK, 1988; MORILAK, 1989; OTAKE, 1992; ROSS, 1985), as quais podem transmitir informações provenientes de quimiorreceptores periféricos (GUYENET, 1996; KOSHIYA, 1993; URBANSKI, 1998). A existência de mecanismos pressores e depressores no NTS podem ser comprovadas mediante injeções em diferentes subáreas (caudal ou rostral, respectivamente) do NTS ou mediante a condição fisiológica do animal (acordado ou anestesiado, respectivamente). Injeções de Lglutamato no NTS em ratos não anestesiados promove respostas pressora e bradicardica, respostas essas semelhante à ativação dos quimiorreceptores periféricos, enquanto que em ratos anestesiados, as respostas observadas foram de hipotensão e bradicardia, semelhante à ativação dos mecanismos barorreceptores (MACHADO, 1992). A resposta pressora, após a injeção do L-glutamato no NTS de ratos anestesiados, foi abolida após a administração do bloqueador de aminoácidos excitatórios, ácido quinurênico, na região do RVL, o que sugere a existência de uma via excitatória originada no NTS que tem projeção para a região RVL (ZAGON, 1996; URBANSKI, 1988). Com o bloqueio dos receptores glutamatérgicos do NTS simultaneamente com a inibição do CVL, ocorre uma redução da pressão arterial, sugerindo a importância da integridade dos mecanismos bulbares para regulação da pressão arterial e atividade simpática eferente (MOREIRA, 2005). A importância dos mecanismos excitatórios, para manutenção dos parâmetros cardiovasculares, foi demonstrada experimentalmente mediante lesões eletrolíticas da região do NTScom de ratos espontaneamente hipertensos (SHR). Nos primeiros dias após a lesão do NTScom observou-se uma redução da hipertensão, bem como um completo bloqueio das respostas cardiovasculares originadas pela ativação dos 
quimiorreceptores periféricos (AKEMI SATO et al., 2001).

Embora os mecanismos centrais pela qual a redução da pressão arterial, a bradicardia e a simpatoinibição, causada pela moxonidina, ainda não sejam completamente compreendidos, propomos que o efeito inibitório causado pela moxonidina sobre os neurônios da região comissural do NTS, pode ser devido a uma diminuição da excitabilidade sobre os neurônios pré-motores simpaticos da região RVL/C1, promovendo uma redução da atividade simpática e consequentemente uma diminuição de pressão arterial. Aparentemente, a moxonidina estaria atuando nos neurônios excitatórios do NTScom (descritos acima) que projetam-se para a região RVL/C1.

O mecanismo molecular de ação da moxonidina no NTScom ou na região RVL/C1 ainda é motivo de várias controversas. Especificamente, não está claro se a simpatoinibição provocada pela moxonidina é mediada através de receptores adrenérgicos $\alpha_{2}$ (GUYENET, 1997) ou através de receptores imidazólicos I1 (ERNSBERGER; HAXHIU, 1997). Os nossos resultados sugerem que os efeitos na pressão arterial e simpáticos promovidos pela injeção de moxonidina no NTScom dependa dos receptores adrenérgicos $\alpha_{2}$, uma vez que o bloqueio dos receptores adrenérgicos $\alpha_{2}$ na região do NTScom eliminou os efeitos cardiovasculares e simpáticos produzidos pela moxonidina.

Os receptores adrenérgicos a pertencem a uma família de três subclasses de receptores classificados em: $\alpha_{1}, \alpha_{2}$ e $\alpha_{3}$, com diferentes funções entre os mesmos (LINK et al.,1992). Os receptores adrenérgicos $\alpha_{2}$ estão localizados na membrana plasmática e correspondem a uma das subunidades de receptores responsáveis por mediar as ações fisiológicas das catecolaminas. Ademais, os receptores adrenérgicos $\alpha_{2}$ são alvos de inúmeros agentes farmacológicos e apresentam varias funções fisiológicas como, por exemplo, regulação do tônus vascular, agregação plaquetária, analgesia e balanço eletrolítico, modulando dessa maneira a liberação de noradrenalina nas terminações neuronais adrenérgicas pré-simpáticas. Os agonistas adrenérgicos $\alpha_{2}$ ao ligarem em seus receptores promovem a ativação de uma proteína $\mathrm{G}$, o qual reduz o $\mathrm{AMPc}$, diminuindo a liberação do seu neurotransmissor na fenda sináptica. Possivelmente, esse seria o mecanismo neuromolecular de ação da moxonidina nos neurônios localizados na região comissural do NTS.

A partir de nossos resultados, acreditamos que a moxonidina, além de atuar 
sobre o NTScom para produzir seus efeitos anti-hipertensivos, estaria agindo em receptores adrenérgicos $\alpha_{2}$ para produzir seus efeitos na atividade simpática e pressão arterial. Com os presentes resultados, não podemos concluir que a moxonidina estaria produzindo seus efeitos anti-hipertensivos por agir em receptores imidazólicos, pois não realizamos experimentos mostrando os efeitos da moxonidina na presença de uma antagonista seletivo para receptores imidazólicos. No entanto, utilizamos dois antagonistas seletivos para receptores adrenérgicos $\alpha_{2}$, ioimbina e RX821002. Resultados prévios mostram que injeção previa de ioimbina no $4^{\circ} \mathrm{V}$ reduziu as respostas de hipotensão e bradicardia, induzidas pela moxonidina (MOREIRA et al., 2007). Contrariamente, injeções prévias de prazosin no $4^{\circ} \mathrm{V}$ não foram capazes de afetar os efeitos hipotensores da moxonidina (MOREIRA et al., 2007). Esses resultados seriam mais um indício de que os efeitos cardiovasculares e simpáticos produzidos pela injeção de moxonidina no SNC são possivelmente mediados pela ativação dos receptores adrenérgicos $\alpha_{2}$.

Embora a literatura mostre a região RVL/C1 como sendo a principal região de ação da moxonidina (HEAD, 1999), os resultados apresentados no presente estudo mostram claramente que a moxonidina também pode atuar em outras regiões do tronco encefálico, como a região comissural do NTS, para produzir os seus efeitos terapêuticos, tais como hipotensão e redução da atividade eferente simpática.

\subsection{Efeito comparativo da moxonidina injetada na região comissural do NTS e na região $\mathrm{RVL} / \mathrm{C} 1$}

Como discutido anteriormente, a injeção de moxonidina na região comissural do NTS produziu hipotensão, bradicardia e simpatoinibição em ratos não anestesiados e anestesiados, no entanto, as respostas foram mais pronunciadas quando a moxonidina foi injetado na região RVL/C1.

A região rostroventrolateral do bulbo é fundamental para a geração do tônus vasomotor simpático e, consequentemente, no controle da pressão arterial, pois essa região contém neurônios pré-motores simpáticos que contribuem para atividade simpática (MCALLEN et al., 1997; SUN, 1995). Os neurônios pré-motores simpáticos do RVL podem ser divididos em dois grupamentos neuronais, sendo o grupamento catecolaminérgico C1 e o grupamento não $\mathrm{C} 1$ (não catecolaminérgico). Ambos os grupamentos estão localizados na porção rostral do bulbo ventrolateral e, 
são constituídos de neurônios barosenssíveis que, projetam-se para a coluna intermédio-lateral. Sabe-se ainda que estes neurônios expressar a vesícula para glutamato (VGLUT2) (indicativo de neurônios excitatórios) e possuem receptores adrenérgicos $\alpha_{2}$ e imidazólicos (GUYENET et al., 1994)

Vários são os estudos que mostram a participação da região RVL/C1 nos efeitos anti-hipertensivos produzidos pelos agonistas adrenérgicos $\alpha_{2}$. Estudos in vitro e in vivo sugerem que a moxonidina contribui para a redução da pressão arterial e da atividade simpática devido a uma redução da atividade neuronal da região RVL/C1. Evidências in vitro mostraram que os efeitos inibitórios da moxonidina seriam devidos: a) hiperpolarização pós-sináptica e b) inibição da liberação de glutamato pré-sinápticamente. Ambos esses efeitos seriam mediados por receptores adrenérgicos $\alpha_{2}$ (HAYAR; GUYENET, 2000). Adicionalmente, experimentos in vivo mostraram que injeções de rilmenidina e clonidina (agonistas adrenérgicos $\alpha_{2}$ e imidazólicos) na região RVL/C1 produzem hipotensão, bradicardia e diminuição da atividade simpática eferente, sugerindo que o efeito antihipertensivo dos agonistas adrenérgicos $\alpha_{2}$ e imidazólicos é devido a um efeito direto nos neurônios do RVL/C1 para reduzir atividade simpática para coração e vasos, assim produzindo hipotensão e bradicardia (GOMEZ et al., 1991; HAXHIU et al., 1994; HEAD, 1999). Da mesma maneira descrito para os experimentos in vitro, as respostas anti-hipertensivas da rilmenidina e clonidina foram atenuadas após o bloqueio de receptores adrenérgicos $\alpha_{2}$ (GUYENET, 1997).

No presente estudo, usando dois modelos experimentais (animais anestesiados e não anestesiados), mostramos que a injeção de moxonidina no NTScom também foi eficaz em reduzir os parâmetros cardiovasculares e simpáticos. Esses efeitos também foram revertidos após o uso de antagonistas adrenérgicos $\alpha_{2}$. Possivelmente, os mecanismos neuromoleculares ativados pela moxonidina nos neurônios do NTScom seriam semelhantes aos mecanismos já relatados para a região RVL/C1. Acreditamos nessa hipótese, uma vez que a região do NTScom contém neurônios excitatórios (expressar VGLUT2), intimamente envolvidos com o controle cardiovascular e que projetam-se para a região RVL/C1. Portanto seria plenamente viável que a moxonidina exerça seus efeitos anti-hipertensivos hiperpolarizando os neurônios do NTScom ou inibindo a liberação de glutamato mediante uma inibição pré-sináptica. Dessa maneira, a via encefálica NTScomRVL/C1 estaria comprometida, fazendo com que ocorresse uma redução da 
atividade simpática eferente e consequentemente uma queda da pressão arterial.

A literatura apresenta ideias controversas no que diz respeito à distribuição de receptores adrenérgicos $\alpha_{2}$ e imidazólicos no tronco encefálico. Aparentemente, os receptores adrenérgicos $\alpha_{2}$ estão mais amplamente distribuídos na região do NTS, enquanto os receptores imidazólicos parecem estar em sua maioria localizados na região RVL/C1 (CARRETTIERO et al., 2011; ERNSBERGER et al., 1993, 1994, 1997; ERNSBERGER; HAXHIU, 1997; GOMEZ et al., 1991; GUYENET et al., 1989; HEAD; BURKE, 1998; MAYOROV et al., 1993; NURMINEN et al., 1998; TOLENTINO-SILVA et al., 2000). Em concordância com as evidências descritas acima, Wang e colaboradores (2005), demonstraram que rilmenidina (agonista seletivo para receptores imidazólicos) promoveu uma redução na expressão de $c$-jun mRNA, um marcador de atividade neuronal, na região RVL/C1, mas não na região do NTS. Foi demonstrado que injeções de clonidina na região mais caudal do bulbo ventrolateral são mais eficazes para inibir a atividade simpática em gatos (GATTI et al., 1988). Segundo Bousquet e colaboradores $(1984,1985)$ injeções de agonistas adrenérgicos $\alpha_{2}$ no RVL/C1 de gatos falhou em não conseguir produzir os efeitos anti-hipertensivos. A moxonidina é classicamente classificada como um antihipertensivo de ação central com uma elevada afinidade sobre os receptores imidazolícos localizados na região RVL/C1 e com baixa afinidade para receptores adrenérgicos $\alpha_{2}$. No entanto, nossos e outros resultados mostraram que moxonidina foi capaz de produzir hipotensão e simpatoinibição por uma ação nos neurônios présimpáticos localizados na região RVL/C1 e também na região do NTScom (HEAD, 1999; MOREIRA et al., 2004, 2007; presentes resultados). Mais estudos são necessários para elucidar os mecanismos neuromoleculares envolvidos nas respostas causadas pela moxonidina, bem como na possível interação entre a região do NTScom e a região RVL/C1 nos efeitos anti-hipertensivos produzidos pela moxonidina.

\subsection{Inibição de neurônios pré-motores simpáticos da região RVL/C1 pela injeção de moxonidina na região comissural do NTS}

Em nossos experimentos, a injeção de moxonidina no NTScom produziu uma redução da atividade elétrica dos neurônios pré-motores simpáticos da região RVL/C1 e, consequentemente, uma redução da PA. Todos os neurônios registrados 
na região $\mathrm{RVL} / \mathrm{C} 1$ consistiram de neurônios que eram sensíveis as variações de pressão arterial, isto é, eram neurônios barosenssíveis. Ademais, classificamos esses neurônios em condução rápida (neurônios catecolaminérgicos) e de condução lenta (neurônios não catecolaminérgicos) no que diz respeito a projeção para a coluna intermédio lateral. A nossa amostra de neurônios foi constituída de 15 células, nas quais 10 eram imunorreativas para tirosina hidroxilase, indicando que aproximadamente $70 \%$ da nossa amostra eram de neurônios catecolaminérgicos localizados no bulbo ventrolateral rostral. A injeção de moxonidina no NTScom promoveu uma redução de aproximadamente $28 \%$ da atividade dos neurônios localizados na região RVL/C1, o que está provavelmente associado a uma redução de $25 \%$ da atividade simpática eferente para coração e vasos.

Embora a região RVL/C1 se apresente como o principal local de ação para a simpatoinibição de fármacos anti-hipertensivos de ação central (HEAD, 1999), os presentes dados mostram claramente que a moxonidina pode estar atuando em outra região encefálica para promover a redução dos neurônios pré-motores simpáticos da região $\mathrm{RVL} / \mathrm{C} 1$, promovendo uma redução da atividade simpática eferente e consequente queda de pressão arterial. Dessa maneira, acreditamos que a moxonidina promova uma inibição pré-sináptica nos neurônios localizados no NTScom o que promoveriam uma inibição da via neural NTS-RVL/C1, levando uma hiperpolarizão dos neurônios pré-motores simpáticos do RVL/C1 (Fig. 15).

Figura 15 - Mecanismos neurais de controle cardiovascular.

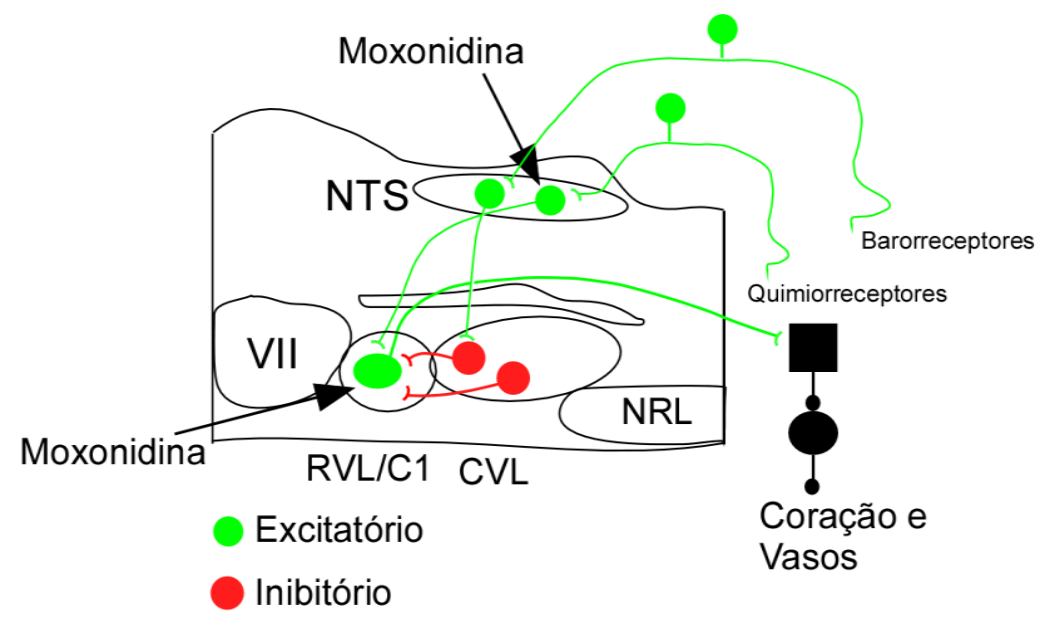

Essa seria a comprovação da nossa hipótese inicial. No entanto, não estamos 
descartando uma ação direta da moxonidina em neurônios pré-motores simpáticos da região RVL/C1, como já foi amplamente demonstrado anteriormente (Fig. 15) (HAYAR; GUYENET, 2000). 


\section{CONCLUSÃO}

Como descrito anteriormente, a moxonidina é um fármaco classificado como um anti-hipertensivo de ação central e tem sua ação preferencialmente na região bulbar em receptores adrenérgicos $\alpha_{2}$ e imidazólicos.

Os nossos resultados mostraram que a moxonidina pode estar atuando também em outra estrutura importante do bulbo (NTScom) para produzir os seus efeitos terapêuticos anti-hipertensivos. No presente trabalho sugerirmos que a moxonidina exerce seus efeitos anti-hipertensivos por agir em receptores adrenérgicos $\alpha_{2}$ na região do NTScom. 


\section{REFERENCIAS ${ }^{\ddagger}$}

AKEMI SATO, M.; VANDERLEI MENANI, J.; UBRÍACO LOPES, O.; COLOMBARI, $E$. Lesions of the commissural nucleus of the solitary tract reduce arterial pressure in spontaneously hypertensive rats. Hypertension, v. 38, p. 560-564, 2001.

ALEXANDER, R. S. Tonic and reflex functions of medullary sympathetic cardiovascular centers. J. Neurophysiol., v. 9, p. 205-207, 1946.

ANDRADE, C. A.; BARBOSA, S. P.; DE LUCA, L. A. JR.; MENANI, J. V. Activation of alpha2-adrenergic receptors into the lateral parabrachial nucleus enhances $\mathrm{NaCl}$ intake in rats. Neuroscience, v. 129, p. 25-34, 2004.

ARMAH, B. I. Unique presynaptic alpha 2-receptor selectivity and specificity of the antihypertensive agent moxonidine. Arzneimittelforschung, v. 38, p. 1435-1442, 1988.

BARMAN, S. M.; GEBBER, G. L. Basis for the naturally occurring activity of rostral ventrolateral medullary sympathoexcitatory neurons. Prog. Brain. Res., v. 81, p. 117-129, 1989.

BAYLISS, W. M. On the origin from the spinal cord of the vaso-dilator fibres of the hind-limb, and on the nature of these fibres. J. Physiol., v. 26, p. 173-209, 1901.

BHUIYAN, M. E.; WAKI, H.; GOURAUD, S. S.; TAKAGISHI, M.; CUI, H.; YAMAZAKI, T.; KOHSAKA, A.; MAEDA, M. Complex cardiovascular actions of alphaadrenergic receptors expressed in the nucleus tractus solitarii of rats. Exp. Physiol., v. 94, p. 773-784, 2009.

BOUSQUET, P.; FELDMAN , J.; SCHWARTZ, J. Central cardiovascular effects of alpha adrenergic drugs: differences between catecholamines and imidazolines. J. Pharmacol. Exp. Ther., v. 230, p. 232-236, 1984.

BOUSQUET, P.; FELDMAN, J.; SCHWARTZ, J. The medullary cardiovascular effects of imidazolines and some GABA analogues: a review. J. Auton Nerv. Syst., v. 14, p. $263-270,1985$.

BROWN, D. L.; GUYENET, P. G. Electrophysiological study of cardiovascular neurons in the rostral ventrolateral medulla in rats. Circ. Res., v. 56, p. 359-369, 1985.

BUCCAFUSCO, J. J.; LAPP, C. A.; WESTBROOKS, K. L.; ERNSBERGER, P. Role of medullary I1-imidazoline and alpha 2-adrenergic receptors in the antihypertensive responses evoked by central administration of clonidine analogs in conscious

\footnotetext{
‡ De acordo com:

ASSOCIAÇÃO BRASILEIRA DE NORMAS TÉCNICAS. NBR 6023: informação e documentação: referências: elaboração. Rio de Janeiro, 2002.
} 
spontaneously hypertensive rats. J. Pharmacol. Exp. Ther., v. 273, p. 1162-1171, 1995.

CARRETTIERO, D. C.; FERRARI, M. F.; FIOR-CHADI, D. R. a2-Adrenergic receptor distribution and density within the nucleus tractus solitarii of normotensive and hypertensive rats during development. Auton Neurosci., v. 166, p. 39-46, 2012.

CHALMERS, J.; PILOWSKY, P. Brainstem and bulbospinal neurotransmitter systems in the control of blood pressure. J. Hypertens., v. 9, p. 675-694, 1991.

CHAN, C. K.; HEAD, G. A. Relative importance of central imidazoline receptors for the antihypertensive effects of moxonidine and rilmenidine. J. Hypertens., v. 14, p. 855-864, 1996.

CHITRAVANSHI, V. C.; KACHROO, A.; SAPRU, H. N. A midline area in the nucleus commissuralis of NTS mediates the phrenic responses to carotid chemoreceptor stimulation. Am. J. Physiol., v. 264, p. 41-50, 1993.

CIRIELLO, J.; HOCHSTENCACH, S. L.; RODER, S. Central projections of baroreceptor and chemoreceptor afferent fibers in the rat. In: BARROCO, A. Nucleus of the solitary tract. Boca Raton, FL: CRC Press, Inc., 1994. p. 35-50.

CIRIELLO, J.; SIMON, J. K.; MERCER, P. F. Effect of renal denervation on plasma renin activity after aortic baroreceptor deafferentation. Can. J. Physiol. Pharmacol. v. 69, p. $1237-1242,1991$.

COLOMBARI, D. S.; PEDRINO, G. R.; FREIRIA-OLIVEIRA, A. H.; KORIM, W. S.; MAURINO, I. C.; CRAVO, S. L. Lesions of medullary catecholaminergic neurons increase salt intake in rats. Brain Res. Bull., v. 76, p. 572-578, 2008.

COLOMBARI, E.; MENANI, J. V.; TALMAN, W. T. Commissural NTS contributes to pressor responses to glutamate injected into the medial NTS of awake rats. Am. J. Physiol., v. 270, p. 1220-1225, 1996.

COLOMBARI, E.; BONAGAMBA, L. G.; MACHADO, B. H. Mechanisms of pressor and bradycardic responses to L-glutamate microinjected into the NTS of conscious rats. Am. J. Physiol., v. 266, p. 730-738, 1994.

COTTLE, M. K. Degeneration studies of primary afferents of IXth and Xth cranial nerves in the cat. J. Comp. Neurol., v. 122, p. 329-345, 1964.

CRUZ, J. C.; BONAGAMBA, L. G.; STERN, J. E.; MACHADO, B. H. Fos expression in the NTS in response to peripheral chemoreflex activation in awake rats. Auton. Neurosci., v. 152, p. 27-34, 2010.

DAMPNEY, R. A. The subretrofacial vasomotor nucleus: anatomical, chemical and pharmacological properties and role in cardiovascular regulation. Prog. Neurobiol., v. 42, p. 197-227, 1994. 
DE PAULA, P. M.; MACHADO, B. H. Changes in regional vascular resistance in response to microinjection of L-glutamate into different antero-posterior coordinates of the RVLM in awake rats. Auton Neurosci., v. 82, p. 137-145, 2000.

DUALE, H.; WAKI, H.; HOWORTH, P.; KASPAROV, S.; TESCHEMACHER, A. G.; PATON, J. F. Restraining influence of A2 neurons in chronic control of arterial pressure in spontaneously hypertensive rats. Cardiovasc. Res., v. 76, p. 184-193, 2007.

EDWARDS, L. P.; BROWN-BRYAN, T. A.; MCLEAN, L.; ERNSBERGER, P. Pharmacological properties of the central antihypertensive agent, moxonidine. Cardiovasc. Ther., v. 30, p. 199-208, 2012.

ERICKSON, J. T.; MILLHORN, D. E. Fos-like protein is induced in neurons of the medulla oblongata after stimulation of the carotid sinus nerve in awake and anesthetized rats. Brain Res., v. 567, p. 11-24, 1991.

ERNSBERGER, P.; DAMON, T. H.; GRAFF, L. M.; SCHÄFER, S. G.; CHRISTEN, M. O. Moxonidine, a centrally acting antihypertensive agent, is a selective ligand for 11 imidazoline sites. J. Pharmacol. Exp. Ther., v. 264, p. 172-182, 1993.

ERNSBERGER, P.; FRIEDMAN, J. E.; KOLETSKY, R. J. The I1-imidazoline receptor: from binding site to therapeutic target in cardiovascular disease. $\mathbf{J}$. Hypertens. Suppl., v. 15, p. 9-23, 1997a.

ERNSBERGER, P.; HAXHIU, M. A. The I1-imidazoline-binding site is a functional receptor mediating vasodepression via the ventral medulla. Am. J. Physiol., v. 273, p. 1572-1579, 1997b.

ERNSBERGER, P.; HAXHIU, M. A.; GRAFF, L. M.; COLLINS, L. A.; DRESHAJ, I.; GROVE, D. L.; GRAVES, M. E.; SCHÄFER, S. G.; CHRISTEN, M. O. A novel mechanism of action for hypertension control: moxonidine as a selective I1imidazoline agonist. Cardiovasc. Drugs. Ther., v. 8, p. 27-41, 1994.

FELDBERG, W.; GUERTZENSTEIN, P. G. Vasodepressor effects obtained by drugs acting on the ventral surface of the brain stem. J. Physiol., v. 258, p. 337-355, 1976.

FELDBERG, W.; GUERTZENSTEIN, P. G. A vasodepressor effect of pentobarbitone sodium. J. Physiol., v. 224, p. 83-103, 1972.

FINLEY, J. C.; KATZ, D. M The central organization of carotid body afferent projections to the brainstem of the rat. Brain Res., v. 572, p. 108-116, 1992.

FUSSEY, I. F.; KIDD, C.; WHITWAM, J. G. Single unit activity, associated with cardiovascular events in the brain stem of the dog. J. Physiol., v. 191, p. 57-58, 1967.

GATTI, P. J.; HILL, K. J.; DA SILVA, A. M.; NORMAN, W. P.; GILLIS, R. A. Central nervous system site of action for the hypotensive effect of clonidine in the cat. $\mathbf{J}$. Pharmacol. Exp. Ther., v. 245, p. 373-380, 1988. 
GOMEZ, R. E.; ERNSBERGER, P.; FEINLAND, G.; REIS D. J. Rilmenidine lowers arterial pressure via imidazole receptors in brainstem $\mathrm{C} 1$ area. Eur. J. Pharmacol., v. 195, p. 181-191, 1991.

GRANATA, A. R. Modulatory inputs on sympathetic neurons in the rostral ventrolateral medulla in the rat. Cell. Mol. Neurobiol., v. 23, p. 665-680, 2003.

GUERTZENSTEIN, P. G. Blood pressure effects obtained by drugs applied to the ventral surface of the brain stem. J. Physiol., v. 229, p. 395-408, 1973.

GUERTZENSTEIN, P. G. Vasodepressor and pressor responses to drugs topically applied to the ventral surface of the brain stem. J. Physiol., v. 224, p. 84-85, 1972.

GUERTZENSTEIN, P. G.; LOPES, O. U. Cardiovascular responses evoked from the nicotine-sensitive area on the ventral surface of the medulla oblongata in the cat. $\mathbf{J}$. Physiol., v. 347, p. 345-360, 1984.

GUERTZENSTEIN, P. G.; SILVER, A. Fall in blood pressure produced from discrete regions of the ventral surface of the medulla by glycine and lesions. J. Physiol., v. 242, p. 489-503, 1974.

GUYENET, P. G. Is the hypotensive effect of clonidine and related drugs due to imidazoline binding sites? Am. J. Physiol., v. 273, p. 1580 -1584, 1997.

GUYENET, P. G. Role of the ventral medulla oblongata in blood pressure regulation. In: LOEWY, A. D.; SPYER, K. M. (Ed.). Central regulation of autonomic functions. New York: Oxford University Press, 1990. p. 145-167.

GUYENET, P. G. The sympathetic control of blood pressure. Nat. Rev. Neurosci., v. 7, p. 335-346, 2006.

GUYENET, P. G.; FILTZ, T. M.; DONALDSON, S. R. Role of excitatory amino acids in rat vagal and sympathetic baroreflexes. Brain Res., v. 407, p. 272-284, 1987.

GUYENET, P. G.; HASELTON, J. R.; SUN, M. K. Sympathoexcitatory neurons of the rostroventrolateral medulla and the origin of the sympathetic vasomotor tone. Prog. Brain Res., v. 8, p. 105-116, 1989.

GUYENET, P. G.; STORNETTA, R. L.; RILEY, T.; NORTON, F. R.; ROSIN, D. L.; $\mathrm{LYNCH}, \mathrm{K}$. R. Alpha 2A-adrenergic receptors are present in lower brainstem catecholaminergic and serotonergic neurons innervating spinal cord. Brain. Res., v. 638, p. 285-294, 1994.

HAIBARA, A. S.; COLOMBARI, E.; CHIANCA D. A. JR.; BONAGAMBA, L. G.; MACHADO B. H. NMDA receptors in NTS are involved in bradycardic but not in pressor response of chemoreflex. Am. J. Physiol., v. 269, p. 1421-1427, 1995.

HANCOCK, M. B. Evidence for direct projections from the nucleus of the solitary tract onto medullary adrenaline cells. J. Comp. Neurol., v. 276, p. 460-468, 1988. 
HAXHIU, M. A.; DRESHAJ, I.; SCHÄFER, S. G.; ERNSBERGER, P. Selective antihypertensive action of moxonidine is mediated mainly by 11 -imidazoline receptors in the rostral ventrolateral medulla. J. Cardiovasc. Pharmacol., v. 24, p. 1-8, 1994.

HAYAR, A.; GUYENET, P. G. Prototypical imidazoline-1 receptor ligand moxonidine activates alpha2-adrenoceptors in bulbospinal neurons of the RVL. J. Neurophysiol., v. 83, p. 766-776, 2000.

HEAD, G. A.; BURKE, S. L.; CHAN, C. K. Central imidazoline receptors and centrally acting anti-hypertensive agents. Clin. Exp. Hypertens., v. 19, p. 591-605, 1997.

HEAD, G. A.; CHAN, C. K.; BURKE, S. L. Relationship between imidazoline and alpha2-adrenoceptors involved in the sympatho-inhibitory actions of centrally acting antihypertensive agents. J. Auton. Nerv. Syst., v. 72, p. 163-169, 1998.

HEAD, G. A. Central imidazoline- and alpha 2-receptors involved in the cardiovascular actions of centrally acting antihypertensive agents. Ann. N. Y. Acad. Sci., v. 881, p. 279-286, 1999.

HORIUCHI, J.; DAMPNEY, R. A. Evidence for tonic disinhibition of RVLM sympathoexcitatory neurons from the caudal pressor area. Auton. Neurosci., v. 99, p. 102-110, 2002.

ITO, S.; SVED, A. F. Tonic glutamate-mediated control of rostral ventrolateral medulla and sympathetic vasomotor tone. Am. J. Physiol. Regul. Integr. Comp. Physiol., v. 273, p. 487-494, 1997.

JESKE, I.; MORRISON, S.F.; CRAVO, S. L.; REIS, D. J. Identification of baroreceptor reflex interneurons in the caudal ventrolateral medulla. Am. J. Physiol. Regul. Integr. Comp. Physiol., v. 264, p. 169-178, 1993.

JESKE, I.; REIS, D. J.; MILNER, T. A. Neurons in the barosensory area of the caudal ventrolateral medulla project monosynaptically on to sympathoexcitatory bulbospinal neurons in the rostral ventrolateral medulla. Neuroscience, v. 65, p. 343-353, 1995.

JORDAN, D.; SPYER, K. M. Is presynaptic inhibition responsible for suppression of the baroreceptor reflex during the defence reaction [proceedings]. J. Physiol., v. 271, p. 58-59, 1977.

JORDAN, D.; SPYER, K. M. The excitability of sinus nerve afferent terminals during the respiratory cycle [proceedings]. J. Physiol., v. 277, p. 66, 1978.

KOSHIYA, N.; GUYENET, P. G. NTS neurons with carotid chemoreceptor inputs arborize in the rostral ventrolateral medulla. Am. J. Physiol., v. 270, p. 1273-1278, 1996.

LEONE, C.; GORDON, F. J. Is L-glutamate a neurotransmitter of baroreceptor information in the nucleus of the tractus solitarius? J. Pharmacol. Exp. Ther., v. 250, p. 953-962, 1989. 
KOSHIYA, N.; HUANGFU, D.; GUYENET, P. G. Ventrolateral medulla and sympathetic chemoreflex in the rat. Brain Res., v. 609, p. 174-184, 1993.

LINK, R. E.; DAUNT, D.; BARSH, G.; CHRUSCINSKI, A.; KOBILKA, B. K. Cloning of two mouse genes encoding $\alpha_{2}$-adrenergic receptor subtypes and identification of $a$ single amino acid in the mousea2-C10 homolog responsible for an interspecies variation in antagonist binding. Mol. Pharmacol., v. 42, p. 16-27, 1992.

LIPSKI, J. Antidromic activation of neurones as an analytic tool in the study of the central nervous system. J. Neurosci. Methods., v. 4, p. 1-32, 1981.

LOEWY, A. D. Central autonomic pathways. In: LOWEY, A. D.; SPYER. K. M. Central regulation of autonomic functions. New York: Oxford University Press, 1990. p. 88-103.

LORENZ, W.; LOMASNEY, J. W.; COLLINS, S.; REGAN, J. W.; CARON, M. G.; LEFKOWITZ, R. J. Expression of three alpha 2-adrenergic receptor subtypes in rat tissues: implications for alpha 2 receptor classification. Mol. Pharmacol., v. 38, p. 599-603, 1990.

MACHADO, B. H. Neurotransmission of the cardiovascular reflexes in the nucleus tractus solitarii of awake rats. Ann. N. Y. Acad. Sci., v. 940, p. 179-196, 2001.

MACHADO, B. H.; BONAGAMBA, L. G. Microinjection of L-glutamate into the nucleus tractus solitarii increases arterial pressure in conscious rats. Brain Res., v. 576, p. 131-138, 1992.

MAYOROV, D.; CHERNOBELSKI, M.; MEDVEDEV, O. Sympathoinhibitory action of rilmenidine in conscious sinoaortically denervated rats. J. Cardiovasc. Pharmacol., v. 22, p. 314-320, 1993.

MCALLEN, R. M.; MALPAS, S. C. Sympathetic burst activity: characteristics and significance. Clin. Exp. Pharmacol. Physiol., v. 24, p. 791-799, 1997.

MITROVIC, V.; PATYNA, W.; HÜTING, J.; SCHLEPPER, M. Hemodynamic and neurohumoral effects of moxonidine in patients with essential hypertension. Cardiovasc. Drugs. Ther., v. 5, p. 967-972, 1991.

MOREIRA, T. S.; TAKAKURA, A. C. Commentaries on Viewpoint: Initiating inspiration outside the medulla does produce eupneic breathing. What is the role of brain stem neurons in eupneic breathing. AC. J. Appl. Physiol., v. 110, p. 854-856, 2011.

MOREIRA, T. S.; SATO, M. A.; TAKAKURA, A. C.; MENANI, J. V.; COLOMBARI, E. Role of pressor mechanisms from the NTS and CVLM in control of arterial pressure. Am. J. Physiol. Regul. Integr. Comp. Physiol., v. 289, p. 1416-1425, 2005.

MOREIRA, T. S.; TAKAKURA, A. C.; COLOMBARI, E.; DE LUCA, L. A. JR.; RENZI, A.; MENANI, J. V. Central moxonidine on salivary gland blood flow and cardiovascular responses to pilocarpine. Brain Res., v. 987, p. 155-163, 2003. 
MOREIRA, T. S.; TAKAKURA, A. C.; COLOMBARI, E.; GUYENET, P. G. Central chemoreceptors and sympathetic vasomotor outflow. J. Physiol., v. 577, p. 369386, 2006.

MOREIRA, T. S.; TAKAKURA, A. C.; COLOMBARI, E.; MENANI, J. V. Antihypertensive effects of central ablations in spontaneously hypertensive rats. Am. J. Physiol. Regul. Integr. Comp. Physiol., v. 296, p. 1797-1806, 2009.

MOREIRA, T. S.; TAKAKURA, A. C.; MENANI, J. V.; COLOMBARI, E. Involvement of central alpha1- and alpha2-adrenoceptors on cardiovascular responses to moxonidine. Eur. J. Pharmacol., v. 563, p. 164-171, 2007.

MOREIRA, T. S.; TAKAKURA, A. C.; MENANI, J. V.; SATO, M. A.; COLOMBARI, E. Central blockade of nitric oxide synthesis reduces moxonidine-induced hypotension. Br. J. Pharmacol., v. 142, p. 765-771, 2004.

MOREIRA, T. S.; THOMAZ, A. C.; DE LUCA, L. A. JR.; RENZI, A.; MENANI, J. V. Moxonidine reduces pilocarpine-induced salivation in rats. Auton Neurosci., v. 91, p. 32-36, 2001.

MORILAK, D. A.; SOMOGYI, P.; MCILHINNEY, R. A.; CHALMERS, J. An enkephalin-containing pathway from nucleus tractus solitarius to the pressor area of the rostral ventrolateral medulla of the rabbit. Neuroscience, v. 31, p. 187-194, 1989.

MORRISON, S. F.; REIS, D. J. Responses of sympathetic preganglionic neurons to rostral ventrolateral medullary stimulation. Am. J. Physiol., v. 261, p. 1247-1256, 1991.

MORRISON, S. F.; REIS, D. J. Reticulospinal vasomotor neurons in the RVL mediate the somatosympathetic reflex. Am. J. Physiol., v. 256, p. 1084-1097, 1989.

NURMINEN, M. L.; CULMAN, J.; HAASS, M.; CHUNG, O.; UNGER, T. Effect of moxonidine on blood pressure and sympathetic tone in conscious spontaneously hypertensive rats. Eur. J. Pharmacol., v. 362, p. 61-67, 1998.

OHTA, H.; TALMAN, W. T. Both NMDA and non-NMDA receptors in the NTS participate in the baroreceptor reflex in rats. Am. J. Physiol., v. 267, p. 1065-1070, 1994.

OTAKE, K.; EZURE, K.; LIPSKI, J.; WONG SHE, R. B. Projections from the commissural subnucleus of the nucleus of the solitary tract: an anterograde tracing study in the cat. J. Comp. Neurol., v. 324, p. 365-378, 1992.

PALKOVITS, M.; ZÁBORSZKY, L. Neuroanatomy of central cardiovascular control. Nucleus tractus solitarii: afferent and efferent neuronal connections in relation to the baroreceptor reflex arc. Prog. Brain Res., v. 47, p. 29-34, 1977. 
PAXINOS, G.; WATSON, C. The rat brain: in stereotaxic coordinates. San Diego: Academic Press, 1998.

PINAULT, D. A. Novel single-cell staining procedure performed in vivo under electrophysiological control: morpho-functional features of juxtacellularly labeled thalamic cells and other central neurons with biocytin or Neurobiotin. J. Neurosci. Methods, v. 65, p. 113-136, 1996.

PLÄNITZ, V. Crossover comparison of moxonidine and clonidine in mild to moderate hypertension. Eur. J. Clin. Pharmacol., v. 27, p. 147-152, 1984.

PUNNEN, S.; URBANSKI, R.; KRIEGER, A. J.; SAPRU, H. N. Ventrolateral medullary pressor area: site of hypotensive action of clonidine. Brain Res., v. 422, p. 336-346, 1987.

REIS, D. J. Neurons and receptors in the rostroventrolateral medulla mediating the antihypertensive actions of drugs acting at imidazoline receptors. J. Cardiovasc. Pharmacol., v. 27, p. 11-18, 1996.

REIS, D. J.; PILETZ, J. E. The imidazoline receptor in control of blood pressure by clonidine and allied drugs. Am. J. Physiol., v. 273, p. 1569-1571, 1997.

RODER, S.; CIRIELLO, J. Caudal ventrolateral medullary projections to the nucleus of the solitary tract in the cat. Neurosci. Lett., v. 134, p. 161-164, 1992.

ROSS, C. A.; RUGGIERO, D. A.; PARK, D. H.; JOH, T. H.; SVED, A. F.; FERNANDEZ-PARDAL, J.; SAAVEDRA, J. M.; REIS, D. J. Tonic vasomotor control by the rostral ventrolateral medulla: effect of electrical or chemical stimulation of the area containing $\mathrm{C} 1$ adrenaline neurons on arterial pressure, heart rate, and plasma catecholamines and vasopressin. J. Neurosci., v. 4, p. 474-494, 1984.

ROSS, C. A.; RUGGIERO, D. A.; REIS, D. J. Projections from the nucleus tractus solitarii to the rostral ventrolateral medulla. J. Comp. Neurol., v. 242, p. 511-534, 1985.

SASAKI, S.; LI, Y. W.; DAMPNEY, R. A. Comparison of the pressor effects of angiotensin II and III in the rostral ventrolateral medulla. Brain Res., v. 600, p. 335338, 1993.

SATO, M. A.; MENANI, J. V.; LOPES, O. U.; COLOMBARI. E. Commissural NTS lesions and cardiovascular responses in aortic baroreceptor-denervated rats. Hypertension, v. 34, p. 739-743, 1999.

SCHLICKER, E.; ARMAH, B. I.; GÖTHERT, M. Central presynaptic alpha 2autoreceptors are involved in the blood pressure-lowering effect of moxonidine. $\mathbf{J}$. Cardiovasc. Pharmacol., v. 16, p. 15-22, 1990.

SCHREIHOFER, A. M.; GUYENET, P. G. Identification of C1 presympathetic neurons in rat rostral ventrolateral medulla by juxtacellular labeling in vivo. J. Comp. Neurol., v. 387, p. 524-536, 1997. 
SCHREIHOFER, A. M.; GUYENET, P. G. The baroreflex and beyond: control of sympathetic vasomotor tone by GABAergic neurons in the ventrolateral medulla. Clin. Exp. Pharmacol. Physiol., v. 29, p. 514-521, 2002.

SICA, D. A. Centrally acting antihypertensive agents: an update. J. Clin. Hypertens., v. 9, p. 399-405, 2007.

SPYER, K. M. The central nervous organization of reflex circulatory control. In: , LOWEY, A. C.; SPYER, K. M. Central regulation of autonomic functions. New York: Oxford, 1990a. p. 168-188.

SPYER, K. M.; IZZO, P. N; LIN, R. J.; PATON, J. F. R.; SILVA-CARVALHO, L. F.; RICHTER, D. W. The central organization of the carotid body chemoreceptor reflex. In: ACKER, H. Chemoreceptors and chemoreceptors reflexes. New York: Pelum Press, 1990b. p. 317-321.

STORNETTA, R. L.; GUYENET, P.G. Distribution of glutamic acid decarboxylase mRNA-containing neurons in rat medulla projecting to thoracic spinal cord in relation to monoaminergic brainstem neurons. J. Comp. Neurol., v. 407, p. 367-380, 1999.

STORNETTA, R. L.; MCQUISTON, T. J.; GUYENET, P. G. GABAergic and glycinergic presympathetic neurons of rat medulla oblongata identified by retrograde transport of pseudorabies virus and in situ hybridization. J. Comp. Neurol., v. 479, p. 257-270, 2004.

SUN, M. K. Central neural organization and control of sympathetic nervous system in mammals. Prog. Neurobiol., v. 47, p. 157-233, 1995.

SVED, A. F.; ITO, S.; MADDEN, C. J. Baroreflex dependent and independent roles of the caudal ventrolateral medulla in cardiovascular regulation. Brain Res. Bull., v. 51, p. 129-133, 2000.

SZABO, B. Imidazoline antihypertensive drugs: a critical review on their mechanism of action. Pharmacol. Ther., v. 93, p. 1-35, 2002.

TAKAKURA, A. C.; DOS SANTOS MOREIRA, T.; DE LUCA, L. A. JR.; RENZI, A.; MENANI J. V. Central alpha(2) adrenergic receptors and cholinergic-induced salivation in rats. Brain Res. Bull., v. 59, p. 383-386, 2003.

TAKAKURA, A. C.; MOREIRA, T. S.; COLOMBARI, D. S.; DE LUCA, L. A. JR.; MENANI J. V. Activation of alpha(2)-adrenoceptors in the lateral hypothalamus reduces pilocarpine-induced salivation in rats. Neurosci. Lett. v. 450, p. 225-228, 2009.

TAKAKURA, A. C.; COLOMBARI, E.; MENANI, J. V.; MOREIRA, T. S. Ventrolateral medulla mechanisms involved in cardiorespiratory responses to central chemoreceptor activation in rats. Am. J. Physiol. Regul. Integr. Comp. Physiol., v. 300, p. 501-510, 2011b. 
TAKAKURA, A. C.; MOREIRA, T. S. Contribution of excitatory amino acid receptors of the retrotrapezoid nucleus to the sympathetic chemoreflex in rats. Exp. Physiol., v. 96, p. 989-999, 2011 a.

TAKAKURA, A. C.; MOREIRA, T. S.; COLOMBAR, E.; WEST, G. H.; STORNETTA, R. L.; GUYENET, P. G. Peripheral chemoreceptor inputs to retrotrapezoid nucleus (RTN) CO2-sensitive neurons in rats. J. Physiol., v. 572, p. 503-523, 2006.

TALMAN, W. T.; PERRONE, M. H.; REIS, D. J. Evidence for L-glutamate as the neurotransmitter of baroreceptor afferent nerve fibers. Science, v. 209, p. 813-815, 1980.

TER HORST, G. J.; STREEFLAND, C. Ascending projections of the solitary tract nucleus. In: ROBIN, I.; BARROCO, A. Nucleus of the solitary tract. Boca Raton, FL: CRC Press, Inc, 1994. p. 93-103.

TOLENTINO-SILVA, F. P.; HAXHIU, M. A.; ERNSBERGER, P.; WALDBAUM, S.; DRESHAJ, I. A. Differential cardiorespiratory control elicited by activation of ventral medullary sites in mice. J. Appl. Physiol., v. 89, p. 437-444, 2000.

TORVIK, A. Afferent connections to the sensory trigeminal nuclei, the nucleus of the solitary tract and adjacent structures; an experimental study in the rat. J. Comp. Neurol., v. 106, p. 51-141, 1956.

URBANSKI, R. W.; SAPRU, H. N. Evidence for a sympathoexcitatory pathway from the nucleus tractus solitarii to the ventrolateral medullary pressor area. J. Auton. Nerv. Syst., v. 23, p. 161-174, 1988.

WANG, S. C.; RANSON, S. W. Autonomic responses to electrical stimulation of the lower brain stem. J. Comp. Neurol., v. 71, p. 437-455, 1939.

WANG, X.; LI, G.; ABDEL-RAHMAN, A. A. Site-dependent inhibition of neuronal cjun in the brainstem elicited by imidazoline 11 receptor activation: role in rilmenidineevoked hypotension. Eur. J. Pharmacol., v. 514, p. 191-199, 2005.

WANG, X.; LI, G.; ABDEL-RAHMAN, A. A. Site-dependent inhibition of neuronal cjun in the brainstem elicited by imidazoline 11 receptor activation: role in rilmenidineevoked hypotension. Eur. J. Pharmacol., v. 514, p. 191-199, 2005.

WESTON, M.; WANG, H.; STORNETTA, R. L.; SEVIGNY, C. P.; GUYENET, P. G. Fos expression by glutamatergic neurons of the solitary tract nucleus after phenylephrine - induced hyprtension in rats. J. Comp. Neurol., v. 460, p. 525-541, 2003.

ZAGON, A.; SPYER, K. M. Stimulation of aortic nerve evokes three different response patterns in neurons of rostral VLM of the rat. Am. J. Physiol. Regul. Integr. Comp. Physiol., v. 271, p. 1720-1728, 1996. 